- Phytoplankton pigment assemblages in the open ocean identified using hyperspectral data

- Potential usefulness of derivative spectroscopy of absorption and remote-sensing reflectance

- Cluster-based approach to identify the most suitable spectral ranges and derivative parameters 


\title{
Cluster analysis of hyperspectral optical data for discriminating phytoplankton pigment assemblages in the open ocean
}

\author{
E. Torrecilla ${ }^{1}$, D. Stramski ${ }^{2}$, R. A. Reynolds ${ }^{2}$, E. Millán-Núñez ${ }^{2,3}$, and J. Piera ${ }^{1}$ \\ ${ }^{1}$ Mediterranean Marine and Environmental Research Centre, Marine Technology Unit (UTM- \\ CSIC), Pg. Marítim Barceloneta 37, Barcelona 08003, Spain (torrecilla@utm.csic.es) \\ ${ }^{2}$ Marine Physical Laboratory, Scripps Institution of Oceanography, University of California San \\ Diego, La Jolla, California 92093-0238, USA \\ ${ }^{3}$ CICESE, Ecología Marina, Carretera Ensenada-Tijuana No. 3918 Fraccionamiento Zona \\ Playitas, Ensenada, B. C., Código Postal 22860, México
}

Keywords: Ocean optics, ocean reflectance, absorption coefficient, phytoplankton pigments, cluster analysis 


\section{Abstract}

1 Optical measurements including remote sensing provide a potential tool for the identification of

2 dominant phytoplankton groups and for monitoring spatial and temporal changes in biodiversity

3 in the upper ocean. We examine the application of an unsupervised hierarchical cluster analysis

4 to phytoplankton pigment data and spectra of the absorption coefficient and remote-sensing

5 reflectance with the aim of discriminating different phytoplankton assemblages in open ocean

6 environments under non-bloom conditions. This technique is applied to an optical and

7 phytoplankton pigment data set collected at several stations within the eastern Atlantic Ocean,

8 where the surface total chlorophyll- $a$ concentration (TChla) ranged from 0.11 to $0.62 \mathrm{mg} \mathrm{m}^{-3}$.

9 Stations were selected on the basis of significant differences in the ratios of the two most

10 dominant accessory pigments relative to TChl $a$, as derived from High Performance Liquid

11 Chromatography (HPLC) analysis. The performance of cluster analysis applied to absorption and

12 remote-sensing spectra is evaluated by comparisons with the cluster partitioning of the

13 corresponding HPLC pigment data, in which the pigment-based clusters serve as a reference for

14 identifying different phytoplankton assemblages. Two indices, cophenetic and Rand, are utilized

15 in these comparisons to quantify the degree of similarity between pigment-based and optical-

16 based clusters. The use of spectral derivative analysis for the optical data was also evaluated, and

17 sensitivity tests were conducted to determine the influence of parameters used in these

18 calculations (spectral range, smoothing filter size, band separation). The results of our analyses

19 indicate that the second derivative calculated from hyperspectral ( $1 \mathrm{~nm}$ resolution) data of the

20 phytoplankton absorption coefficient, $a_{p h}(\lambda)$, and remote-sensing reflectance, $R_{r s}(\lambda)$, provide

21 better discrimination of phytoplankton pigment assemblages than traditional multispectral band-

22 ratios or ordinary (non-differentiated) hyperspectral data of absorption and remote-sensing

23 reflectance. The most useful spectral region for this discrimination extends generally from 
24 wavelengths of about 425 - $435 \mathrm{~nm}$ to wavelengths within the $495-540 \mathrm{~nm}$ range, although in 25 the case of phytoplankton absorption data a broader spectral region can also provide satisfactory 26 results.

27 


\section{Introduction}

In situ and remotely-sensed optical observations of ocean waters provide information

30 regarding the concentrations of optically significant constituents in seawater, and offer the ability

31 to observe important biological and biogeochemical variables (e.g., Chang et al., 2006).

32 Numerous studies over the past three decades have focused on the development of bio-optical

33 algorithms linking measurable optical properties to the primary pigment in phytoplankton,

34 chlorophyll- $a$, a proxy for the phytoplankton biomass (e.g., Morel, 1988; Bricaud et al., 1998;

35 O'Reilly et al., 2000; Reynolds et al., 2001). In recent years, efforts to expand the use of optical

36 measurements for estimating other biogeochemically important ocean variables and phenomena

37 have increased considerably. For example, optical measurements including satellite remote

38 sensing have been used to detect harmful algal blooms (Cullen et al., 1997; Stumpf et al., 2003),

39 surface concentrations of particulate inorganic and organic carbon (Balch et al., 2005; Stramski

40 et al., 2008), particle size distribution (Kostadinov et al., 2009), phytoplankton community

41 composition and size structure (Alvain et al., 2005; Uitz et al., 2006; Nair et al., 2008; Ciotti and

42 Bricaud, 2006; Aiken et al., 2007), and phytoplankton class-specific primary production (Uitz et

43 al., 2010).

44 Recent advances in measuring ocean optical properties and light fields within and leaving the

45 ocean have included a progressive shift from using multispectral to high spectral resolution

46 (hyperspectral) acquisition systems (Chang et al., 2004). New technologies and the

47 miniaturization of electro-optical components have permitted the development of accurate, low-

48 cost, and energy-efficient hyperspectral sensors suitable for deployments from a variety of

49 platforms such as in-water vertical profiling systems, moorings, drifters, autonomous vehicles,

50 air-borne and space-borne platforms (Perry \& Rudnick, 2003; Dickey et al., 2006). The

51 capability to obtain measurements at hundreds of narrow and closely spaced wavelength bands

52 from the ultraviolet to near-infrared, with a resolution better than $10 \mathrm{~nm}$, has become one of the 
53 most powerful and fastest growing areas of technology in the field of ocean optics.

54 Hyperspectral optical data provide the opportunity for improvements in spectral shape

55 analysis and subsequent extraction of environmental information compared with low spectral

56 resolution optical data. Derivative spectroscopy is one powerful technique of spectral shape

57 analysis which enhances subtle features in hyperspectral data, and has been used successfully to

58 obtain information about optically significant water constituents. For example, Craig et al.

59 (2006) assessed the feasibility of detection of a toxic bloom of the dinoflagellate Karenia brevis

60 from the analysis of the fourth derivative of phytoplankton absorption spectra, estimated from in

61 situ hyperspectral measurements of remote-sensing reflectance $R_{r s}(\lambda)$ ( $\lambda$ is light wavelength in

62 vacuo). The advantages offered by hyperspectral measurements of $R_{r s}(\lambda)$ in combination with

63 derivative spectroscopy for identifying algal blooms were also demonstrated by Lubac et al.

64 (2008), who based their analysis on the position of the maxima and minima of the second

65 derivative of the spectral $R_{r s}(\lambda)$. Louchard et al. (2002) assessed major sediment pigments of

66 benthic substrates from derivative spectra of hyperspectral $R_{r s}(\lambda)$ measured in shallow marine

67 environments. In general, the optical detection of specific algal blooms appears feasible because

68 certain accessory pigments with specific absorption features are unique to individual

69 phytoplankton taxa and can be better differentiated in hyperspectral absorption data than in

70 multispectral data with a limited number of wavelengths.

71 The advantages and increasing availability of high spectral resolution measurements suggest

72 that the effectiveness of hyperspectral optical information for assessing phytoplankton diversity

73 should be further explored. In particular, there is a need to test whether the hyperspectral

74 approach, which has proven useful in inland and coastal waters (e.g., Lee \& Carder, 2004;

75 Hunter et al., 2008; Lubac et al., 2008), can be also effective for the identification of different

76 phytoplankton assemblages at large spatial scales in open ocean waters. These tests are also

77 especially important for the common situation in which various phytoplankton groups co-exist at

78 significant concentrations, and no single species dominates the assemblage (i.e., a non-bloom 
condition).

80 In this study, we analyze phytoplankton pigment data in conjunction with optical data of 81 absorption coefficients and remote-sensing reflectance, which were determined along a north-to-

82 south transect in the eastern Atlantic Ocean. Our primary goal is to examine the feasibility of

83 classifying different open ocean environments under non-bloom conditions in terms of

84 phytoplankton pigment assemblages from analysis of hyperspectral absorption and remote-

85 sensing reflectance measurements. In order to address this question, an unsupervised

86 hierarchical cluster analysis is applied to the pigment data set obtained from High Performance

87 Liquid Chromatography (HPLC) analysis of seawater samples and to the optical data sets

88 including the spectra of absorption coefficients and remote-sensing reflectance and their second

89 derivative spectra. For this analysis, the pigment data and the corresponding optical data were

90 selected to represent distinct differences in major accessory pigments present in the samples. We

91 view our analysis basically as a proof-of-concept study in which our approach is to use a

92 relatively small but carefully selected set of data which exhibits significant contrasts in the

93 composition of pigments, rather than to indiscriminately use large data sets. The pigment-based

94 clusters provide a reference for partitioning the selected data set into distinct subsets, each

95 characterized by different phytoplankton pigment composition. Two indices, cophenetic and

96 Rand, are examined to quantify the degree of similarity between the pigment-based clusters and

97 optical-based clusters, and are ultimately used to illustrate the effectiveness of optical

98 classification. The degree of similarity between clusters was evaluated for calculations involving

99 different spectral ranges of optical data. Because the quality of derivative analysis also depends

100 on parameters involved in data processing and computations, especially smoothing filter size and

101 derivative band separation (Tsai \& Philpot, 1998; Lee \& Carder, 2002; Vaiphasa, 2006), a

102 sensitivity of cluster analysis to the choice of these parameters was performed.

103 


\section{Measurements and Data Analysis}

The approach in this study consists of three main components: (i) collection of field data of

106 phytoplankton pigments and ocean optical properties and selection of a subset of data

107 characterized by distinct differences in major accessory pigments for the cluster analysis, (ii)

108 radiative transfer modeling to compute hyperspectral remote sensing-reflectance, and (iii) cluster

109 analysis of pigment and optical data. The methodology of each component is described below.

\section{2.1. Field measurements}

112 Measurements of phytoplankton pigment composition and seawater optical properties were 113 obtained during the ANT-XXIII/1 expedition of the R/V Polarstern along a north-to-south

114 transect in the eastern Atlantic Ocean during October and November, 2005 (Fig. 1). The

115 investigated area spanned a wide range of different oceanic environments between the English

116 Channel and the waters off the African coast of Namibia. Typically, one full station was

117 conducted daily near local noon throughout the cruise. These full stations consisted of in situ

118 measurements of seawater inherent and apparent optical properties along with laboratory

119 analyses of water samples collected from discrete depths with the ship's CTD/rosette system.

120 For the present study, a subset of nine stations (see Fig. 1 for station locations) was selected for

121 cluster analysis based on the observation of distinct differences in the ratios of dominant

122 accessory pigments to total chlorophyll- $a$ (further details in sec. 3.1). The selected data from the

123 nine stations are representative of surface waters within the top 5-10 $\mathrm{m}$ of the ocean, as our main

124 interest lies in the methodology for estimating variability in phytoplankton communities from

125 remote-sensing reflectance. A brief description of the measurements is provided in the following

126 three subsections. More methodological details, especially for the radiometric and

127 backscattering measurements, can be found in Stramski et al. (2008). 


\subsubsection{HPLC pigment analysis}

130 Concentrations of chlorophyll- $a$ and accessory pigments in phytoplankton were measured on 131 surface water samples from each station using HPLC techniques. Two sets of replicate samples

132 were collected and analyzed at two laboratories, the Center for Hydro-Optics and Remote

133 Sensing (CHORS) laboratory at San Diego State University (California, USA) and the GKSS

134 Research Centre in Geesthacht (Germany). The CHORS analysis was based on a method

135 described in Van Heukelem and Thomas (2001), and the GKSS samples were analyzed following

136 the method of Zapata et al. (2000). The CHORS analysis included identification and

137 quantification of more pigments (27) than the GKKS method (23) including alternative forms of

138 chlorophyll- $a$, and was chosen as the primary pigment data set for identifying phytoplankton

139 assemblages using cluster analysis. Throughout the rest of this paper, as a measure of

140 chlorophyll- $a$ we use the CHORS values of the total chlorophyll- $a$, TChl $a$, which is defined as

141 the summed contributions of concentrations of monovinyl chlorophyll- $a$ (MVChl $a)$, divinyl

142 chlorophyll- $a$ (DVChl $a$ ), chlorophyllide- $a$ (Chlide), and the allomeric and epimeric forms of 143 chlorophyll- $a$.

144 Following completion of our analyses, the potential for errors in the CHORS results was 145 identified. The NASA team tasked with investigating HPLC data quality problems at CHORS 146 recommended that overall "These data are not validated and should not be used as sole basis for

147 a scientific result, conclusion, or hypothesis - independent corroborating evidence is required"

148 (Hooker and Van Heukelem, 2009). Based on field data obtained in the SeaHARRE-3

149 intercalibration experiment, corrections for specific individual pigments (MVChla, DVChla)

150 were developed (C. Trees, personal communication), which are used in our data set in the

151 determination of TChla. These corrections are described in Stramski et al. (2008). The corrected

152 TChl $a$ data exhibit reasonable agreement with fluorometrically-derived chlorophyll

153 measurements, and provide realistic estimates of chlorophyll-specific phytoplankton absorption 
154 coefficients within the red peak of chlorophyll- $a$. We also applied similar corrections to three

155 other pigments in the data set; monovinyl chlorophyll- $b, \beta$-carotene, and alloxanthin. We caution

156 that our corrections were developed from a limited set of pigment data and intercalibration

157 results, and should not be used indiscriminately with other data sets affected by the CHORS data 158 quality problems.

159 We also compared the corrected CHORS results with independent pigment determinations

160 done by GKSS. Some differences in the concentrations of individual pigments between the two

161 data sets were observed. For example, the sum of monovinyl chlorophyll- $a$ (MVChla) and

162 divinyl chlorophyll-a (DVChla) was generally higher (on average by $20 \%$ with a standard 163 deviation of $23 \%$, number of samples 25) for CHORS compared with GKSS. However, the

164 CHORS data yielded more reasonable estimates of chlorophyll-specific phytoplankton 165 absorption.

166 Despite such differences in the estimates of some individual pigment concentrations, with 167 regard to the present application it is important to note that both laboratories provided similar 168 characterization of samples in terms of the relative pigment composition as described by ratios of 169 various individual pigments to TChla. The same dominant accessory pigments for any given 170 station and the same trends in the pigment ratios among the stations were obtained from both sets 171 of HPLC analyses. This is an essential result for our study because in the cluster analysis we 172 utilize only pigment ratios, and not individual pigment concentrations. For the nine stations 173 selected in our analysis, the cluster techniques applied independently to the CHORS and GKSS 174 sets of HPLC pigment ratios yielded a very similar partitioning of stations into clusters. We 175 therefore chose the one set of corrected pigment results from CHORS for all subsequent analyses 176 in this paper (sec. 3.1 presents CHORS-based pigment clusters). This choice is further supported 177 by comparisons of cluster analysis of phytoplankton absorption data with the CHORS and 178 GKSS-based pigment clusters. The measures of cluster similarity (see sec. 2.3) between the 179 absorption-based clusters and pigment-based clusters were found to be similar when either the 
CHORS and GKSS pigment data were used.

181 Because of a large range of pigment compositions across different phytoplankton classes,

182 determinations of phytoplankton composition from HPLC pigment data is not straightforward

183 (e.g., Jeffrey et al., 1997). Whereas certain diagnostic pigments can serve as unambiguous

184 markers for some phytoplankton classes (e.g., peridinin in dinoflagellates, alloxanthin in

185 cryptophytes), many important pigments are shared by more than one algal taxa (e.g.,

186 fucoxanthin in diatoms, haptophytes, chrysophytes, and raphidophytes). Nevertheless, because

187 many of the classes have distinctive suites of marker pigments, HPLC data can be useful for

188 indicating their presence and abundance in a mixed phytoplankton population. Specifically, a

189 useful indication of contributing phytoplankton classes can be obtained from the ratios of the

190 concentrations of specific pigments to chlorophyll- $a$ or the ratios of specific diagnostic pigments

191 to the sum of these diagnostic pigments, because these ratios can differ between taxonomic

192 groups (Mackey et al., 1996; Wright et al., 1996; Vidussi et al., 2001).

193 For each of the nine stations selected in this study, we calculated two sets of pigment ratios

194 for subsequent use in the cluster analysis. The first set of pigment ratios consisted of ratios of

195 the concentration of each individual pigment to the TChla concentration, as obtained from HPLC

196 measurements at the CHORS laboratory. The following 24 pigments were included in these

197 calculations: monovinyl chlorophyll- $a$, divinyl chlorophyll- $a$, chlorophyllide- $a$, chlorophyll- $a$

198 allomer, chlorophyll- $a$ epimer, monovinyl chlorophyll- $b$, divinyl chlorophyll- $b$, chlorophyll- $c 2$,

199 chlorophyll-c3, $\alpha$-carotene, $\beta$-carotene, alloxanthin, diadinoxanthin, diatoxanthin, fucoxanthin,

200 19'-hexanoyloxyfucoxanthin, 19'-butanoyloxyfucoxanthin, neoxanthin, prasinoxanthin,

201 violaxanthin, zeaxanthin, peridinin, pheophorbide- $a$, and lutein. The CHORS pigment data set

202 also included a few additional pigments (chlorophyll-cl, gyroxanthin-diester, and pheophytin- $a$ )

203 which were below the level of detection for the nine stations. These pigments were not included

204 in our cluster analysis as they would have no effect on the results. 
The second set of pigment ratios was based on 8 diagnostic pigments: divinyl chlorophyll- $a$

206 (DVChla), divinyl chlorophyll-b (DVChl $b$ ), alloxanthin (Allo), fucoxanthin (Fuco), 19'-

207 hexanoyloxyfucoxanthin (Hex), 19'-butanoyloxyfucoxanthin (But), peridinin (Peri), and

208 zeaxanthin (Zea). This list of pigments is consistent with that proposed by Vidussi et al. (2001)

209 with the exception that we added DVChl $a$ which is a diagnostic pigment for prochlorophytes.

210 For each station the 8 ratios were calculated by dividing a concentration of a given diagnostic

211 pigment to the sum of the 8 diagnostic pigment concentrations (see Uitz et al., 2006).

\section{2.1.2. Inherent optical properties}

214 The inherent optical properties (IOPs) of seawater have a two-fold application in our study.

215 First, the absorption, scattering, and backscattering coefficients are used to define IOP inputs to 216 radiative transfer simulations that generate hyperspectral data of remote-sensing reflectance (sec.

217 2.2). Second, the total absorption coefficient, $a(\lambda)$, and the phytoplankton absorption coefficient, $218 a_{p h}(\lambda)$, are utilized directly in the cluster analysis (sec. 2.3 and 3.2).

219 The spectral absorption coefficients of particles, $a_{p}(\lambda)$, and colored dissolved organic matter $220(\mathrm{CDOM}), a_{c d o m}(\lambda)$ in $\mathrm{m}^{-1}$, were determined at 1-nm intervals from high spectral resolution 221 measurements on freshly-collected discrete water samples with a point-source integrating cavity 222 absorption meter (PSICAM) over the range 350-750 nm (Röttgers et al., 2005, Röttgers \& 223 Doerffer, 2007). As the PSICAM did not provide data below $350 \mathrm{~nm}$, the $a_{p}(\lambda)$ values within the 224300 to $350 \mathrm{~nm}$ spectral range were obtained from filter pad measurements on discrete water 225 samples collected on GF/F filters and frozen in liquid nitrogen until analysis with a dual-beam 226 spectrophotometer (Lambda 18, Perkin Elmer). The filter pad measurements were made with the 227 transmittance-reflectance (T-R) technique of Tassan and Ferrari $(1995 ; 2002)$ using a correction 228 for the pathlength-amplification factor from Stramska et al. (2006). We have chosen to use the 229 PSICAM data of $a_{p}(\lambda)$ over the majority of the spectrum because the PSICAM technique 230 involves a direct measurement of absorption on particle suspension with minimal scattering 
231 artifacts, which is expected to be generally superior to the filter pad measurements. The data of

$232 a_{c d o m}(\lambda)$ below $350 \mathrm{~nm}$ were obtained from an exponential fit to the PSICAM-measured $a_{c d o m}(\lambda)$.

233 A null point correction based on wavelengths in the far red or near-infrared was applied to all

$234 a_{p}(\lambda)$ and $a_{c d o m}(\lambda)$ spectra. The total spectral absorption coefficient, $a(\lambda)$, was determined as the

235 sum of $a_{p}(\lambda), a_{c d o m}(\lambda)$, and the pure water component, $a_{w}(\lambda)$. The latter was obtained from Pope

236 \& Fry (1997) for the spectral range 380-727 nm and from Fry et al. (2006) for the range 300-379

$237 \mathrm{~nm}$. We note that our primary interest is in the spectral information contained at wavelengths

238 longer than about $350 \mathrm{~nm}$ extending throughout the visible part of the spectrum up to $725 \mathrm{~nm}$

239 where most phytoplankton pigments exhibit significant absorption features. However, data at

240 wavelengths shorter than $350 \mathrm{~nm}$ are useful for our analysis, especially in the context of

241 derivative spectra whose discrete values at specific wavelengths were calculated in our study

242 using data covering a bandwidth on the order of $10-30 \mathrm{~nm}$.

243 The spectra of the phytoplankton absorption coefficient, $a_{p h}(\lambda)$, were determined as a

244 difference between the absorption coefficient of particles, $a_{p}(\lambda)$, and the non-phytoplankton

245 component of particulate absorption, $a_{d}(\lambda)$, which is commonly referred to as detrital absorption.

246 These determinations were based on the T-R filter pad measurements, in which the $a_{d}(\lambda)$ spectra

247 were measured on $\mathrm{GF} / \mathrm{F}$ sample filters following treatment with sodium hypochlorite $\mathrm{NaClO}$

248 (Ferrari and Tassan, 1999). In this treatment, the particles on the sample filter were exposed to a

249 small amount of a $2 \% \mathrm{NaClO}$ solution for several minutes to bleach phytoplankton pigments.

250 The spectral beam attenuation coefficient of particles and CDOM, $c_{p, c d o m}(\lambda)$ in $^{-1}$, was

251 determined at each station from in situ measurements with two single-wavelength C-Star

252 transmissometers (488 and $660 \mathrm{~nm}$; WET Labs, Inc.). Note that the C-star derived values

253 represent the total beam attenuation, $c(\lambda)$, with pure seawater contribution, $c_{w}(\lambda)$, subtracted, i.e.

$254 c_{p, c d o m}(\lambda)=c(\lambda)-c_{w}(\lambda)=a_{p}(\lambda)+a_{c d o m}(\lambda)+b_{p}(\lambda)$, where $b_{p}(\lambda)$ is the spectral scattering

255 coefficient of particles. The values of $b_{p}(\lambda)$ at 488 and $660 \mathrm{~nm}$ were thus calculated from C-Star 
256 attenuation and PSICAM absorption measurements as $b_{p}(\lambda)=c_{p, c d o m}(\lambda)-a_{p}(\lambda)-a_{c d o m}(\lambda)$. A

257 power function fit was then applied to these values to produce the spectral data of $b_{p}(\lambda)$ over the 258 range $300-750 \mathrm{~nm}$ with a $1 \mathrm{~nm}$ resolution. The pure seawater scattering coefficient, $b_{w}(\lambda)$, was 259 calculated using the Buiteveld et al. (1994) equations with measured water temperature and 260 salinity (see Twardowski et al., 2007 and Stramski et al., 2008 for details). The total scattering 261 coefficient, $b(\lambda)$, was obtained as a sum $b_{w}(\lambda)+b_{p}(\lambda)$.

262 The spectral backscattering coefficient, $b_{b}(\lambda)$ in $\mathrm{m}^{-1}$, was determined by combining in situ 263 measurements with three instruments, a Hydroscat-6 and two a- $\beta$ eta sensors (HOBI Labs, Inc.), 264 to yield a total of eight spectral bands: 420, 442, 470, 510, 550, 589, 620, and $671 \mathrm{~nm}$ (Stramski 265 et al. 2008). Because $b_{b}(\lambda)$ is generally expected to be a smooth monotonic function of 266 wavelength, especially in the open ocean under non-bloom conditions, the experimental 267 measurements were fitted to a power function to obtain hyperspectral resolution over the 300-

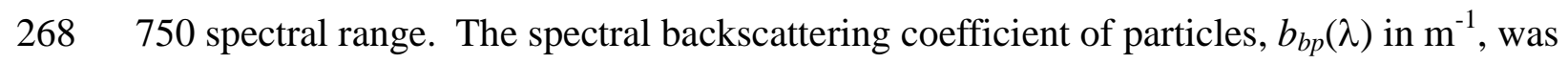
269 determined as a difference between the total and pure seawater backscattering coefficients, $b_{b}(\lambda)$ $270-b_{b w}(\lambda)$, in which the pure seawater component, $b_{b w}(\lambda)$, was calculated as $0.5 b_{w}(\lambda)$.

$271 \quad$ From the values of $b_{p}(\lambda)$ and $b_{b p}(\lambda)$, we calculated the particle backscatter fraction $B_{p}(\lambda)=$ $272 b_{b p}(\lambda) / b_{p}(\lambda)$. These data were then fitted to a power function, $B_{p}(\lambda)=B_{p}\left(\lambda_{0}\right)\left(\lambda_{0} / \lambda\right)^{m}$, where $\lambda_{0}$ 273 is the reference wavelength $550 \mathrm{~nm}$. The backscattering fraction $B_{p}\left(\lambda_{0}\right)$ at the reference 274 wavelength and the exponent $m$ represent the best fit parameters of the linear regression analysis 275 performed for the $\log$-transformed data of $B_{p}(\lambda)$ vs. $\lambda$ for each station. The parameters of the 276 power function fit of $B_{p}(\lambda)$ were used as input to radiative transfer simulations (see sec. 2.2).

\subsubsection{Remote-sensing reflectance}

279 Values of multispectral remote-sensing reflectance, $R_{r s}(\lambda)$ in $\operatorname{sr}^{-1}$, were estimated at each 280 station at 13 wavelengths from in situ measurements of underwater vertical profiles of spectral 281 nadir upwelling radiance, $L_{u}(\lambda, z)$ in $\mathrm{W} \mathrm{m}^{-2} \mathrm{sr}^{-1} \mathrm{~nm}^{-1}$, and spectral downwelling plane irradiance, 
$282 E_{d}(\lambda, z)$ in $\mathrm{W} \mathrm{m}^{-2} \mathrm{~nm}^{-1}$, where $z$ is depth. These measurements were made with a freefall

283 spectroradiometer, the SeaWiFS Profiling Multichannel Radiometer (SPMR, Satlantic, Inc.).

284 The wavelengths for these measurements are 339, 380, 412, 443, 470, 490, 510, 532, 554, 589,

285619,666 , and $683 \mathrm{~nm}$. The radiometric measurements and data processing were consistent with

286 methods recommended in NASA protocols (Mueller et al., 2003).

\subsection{Modeled hyperspectral reflectance}

Because hyperspectral radiometric measurements were not conducted during the ANT$\mathrm{XXIII/1}$ cruise and our primary interest is in the analysis of hyperspectral optical data, we

291 performed numerical simulations of radiative transfer (RT) to estimate the hyperspectral remote-

292 sensing reflectance $R_{r s}(\lambda)$ for each of the nine selected stations. The radiative transfer model

293 Hydrolight/Ecolight version 5.0 (Sequoia Scientific, Inc.) was used (Mobley 1994; 2008). An

294 important prerequisite for undertaking these RT simulations was the availability of a

295 comprehensive suite of IOPs for each station for use as input to the simulations, and also the

296 availability of the multispectral $R_{r s}(\lambda)$ derived from in situ measurements for use in validating 297 the simulated hyperspectral $R_{r s}(\lambda)$.

298 The RT calculations were carried out within the spectral region $300 \mathrm{~nm}$ to $725 \mathrm{~nm}$ with high 299 spectral resolution $(1 \mathrm{~nm})$. Similarly to the absorption, our main interest is in the reflectance data 300 at wavelengths longer than about $350 \mathrm{~nm}$. However, in addition to the requirements associated 301 with derivative calculations, the radiative transfer simulations below $350 \mathrm{~nm}$ are needed to 302 account for Raman scattering contributions observed at $\lambda>350 \mathrm{~nm}$. The ocean was assumed to 303 be infinitely deep and optically homogeneous, and the simulations included the Raman scattering 304 and fluorescence by colored dissolved organic matter within the ocean. The sea surface 305 boundary conditions were estimated from observations of wind speed and sky conditions 306 (cloudiness) at each station site, and the solar zenith angle was calculated for the corresponding 
307 date and geographic coordinates. The inherent optical properties of the water column required as

308 input to the simulations were derived from the IOP measurements in the surface waters and 309 additional relevant determinations of $a(\lambda)$ and $b(\lambda)$ as described in sec. 2.1.2. The selection of

310 the particulate scattering phase function, which is also part of IOP inputs to the RT simulations,

311 was based on the particle backscatter fraction $B_{p}(\lambda)$. We used the Fournier-Forand phase

312 functions which are parameterized in terms of $B_{p}(\lambda)$ and are built into the Hydrolight/Ecolight

313 model.

314 Fig. 2 compares the model-simulated hyperspectral $R_{r s}(\lambda)$ with the measured multispectral

$315 R_{r s}(\lambda)$ for two selected stations. The model results compare reasonably well with measurements, 316 which lends confidence to the use of hyperspectral $R_{r s}(\lambda)$ in our cluster analysis. This level of

317 consistency between the model and measurements suggests that the suite of parameters used as

318 input to the RT simulations realistically represent the actual field conditions. The ability to

319 define realistic inputs derives, in turn, from a comprehensive suite of IOP measurements that 320 were carried out during the cruise.

\subsection{Hierarchical cluster analysis and similarity indices between dendrograms}

323 A hierarchical cluster analysis (HCA) was used to classify the 9 selected stations into distinct 324 groups on the basis of several types of input data vectors (or objects), which included the HPLC 325 pigments and optical data derived from spectral absorption coefficients and remote-sensing 326 reflectance. For a given type of data, the input to the cluster analysis consisted of 9 numerical 327 data vectors, each representing one of the 9 stations. For the input data representing the ratio of 328 individual pigment concentrations to TChla an object for a given station is a data vector $\left\{p_{1}, p_{2}\right.$, $\left.329 p_{3}, \ldots, p_{24}\right\}$ where the consecutive elements $p_{i}$ represent the ratio of each of the 24 individual 330 pigment concentrations to TChla concentration. Another type of pigment data vector used in the 331 cluster analysis is of the form $\left\{d_{1}, d_{2}, d_{3}, \ldots, d_{8}\right\}$, where the consecutive elements represent a ratio 
332 of one of the 8 diagnostic pigment concentrations to the sum of diagnostic pigment

333 concentrations.

334 Several types of optical data vectors were used as input to the HCA analysis, including 335 objects consisting of hyperspectral data of the remote-sensing reflectance, $R_{r s}(\lambda)$, the 336 phytoplankton absorption coefficient, $a_{p h}(\lambda)$, the sum of pure water and phytoplankton 337 absorption coefficients, $a_{w}(\lambda)+a_{p h}(\lambda)$, and the total absorption coefficient, $a(\lambda)$. The input 338 characterizing the hyperspectral remote-sensing reflectance for any given station was used in the 339 form of the following data vector $\left\{R_{r s}\left(\lambda_{1}\right) / R_{r s}(555), R_{r s}\left(\lambda_{2}\right) / R_{r s}(555), R_{r s}\left(\lambda_{3}\right) / R_{r s}(555), \ldots\right.$,

$\left.340 R_{r s}\left(\lambda_{\mathrm{n}}\right) / R_{r s}(555)\right\}$, where the consecutive elements represent the values of $R_{r s}$ at successive light 341 wavelengths normalized to $R_{r s}$ at $555 \mathrm{~nm}$ over the spectral range from $\lambda_{1}$ to $\lambda_{\mathrm{n}}$. Similar input 342 vectors were created for the different components of spectral absorption. Because our analysis is 343 focused on the spectral shapes, all the optical spectra used in the cluster analysis were 344 normalized by the value of the optical variable at $555 \mathrm{~nm}$ at which variations in $R_{r s}$ within the 345 open ocean are generally small. The spectra involving the absorption coefficients were 346 additionally normalized by TChl $a$ concentration to minimize variability in absorption associated 347 with changes in phytoplankton biomass. The rationale for selecting the data of $a(\lambda), a_{w}(\lambda)+$ $348 a_{p h}(\lambda)$, and $a_{p h}(\lambda)$ to create input data vectors for the cluster analysis stems from the fact that the 349 variation in the spectral shape of $a(\lambda)$ is typically a major determinant of the variation in the 350 spectral shape of $R_{r s}(\lambda)$. In turn, the variations in the spectral shape of $a_{w}(\lambda)+a_{p h}(\lambda)$ or $a_{p h}(\lambda)$ 351 can be viewed as an important or dominant source of variation in the spectral shape of $a(\lambda)$ in 352 open ocean situations.

353 We also created vectors from the second derivative spectra of the hyperspectral reflectance 354 and absorption objects for input into the cluster analysis. The estimation of the second derivative 355 spectra from these data was made with a finite divided difference algorithm, the so-called "finite 356 approximation", which computes the changes in curvature of a given spectrum over a sampling 
interval $(\Delta \lambda)$ or band separation $(B S)$ defined as $\Delta \lambda=\lambda_{j}-\lambda_{i}$, where $j>i$. Because the

358 identification of spectral details in the derivative spectra depends on the selection of the band 359 separation, we tested the sensitivity of cluster results to the choice of $B S$. The derivative 360 technique is also sensitive to signal noise, thus smoothing was applied to the hyperspectral 361 optical data prior to computation of derivative spectra. Specifically, a mean-filter smoothing method was used in which the extent of spectral smoothing depends on the size of the filter 363 window (WS) used for averaging. We tested the sensitivity of cluster results to different values 364 of $W S$. The sensitivity analysis over a range of $B S$ and $W S$ values allowed us to achieve the best 365 compromise between the ability to resolve fine spectral details and the reduction of noise effects 366 in the second derivative spectra. As discussed below (sections 3.2 and 3.3), the optimal values of $367 B S$ and $W S$ chosen in this study for the derivative analysis of absorption data are $9 \mathrm{~nm}$. For the 368 derivative analysis of reflectance data, these values are $27 \mathrm{~nm}$. Therefore, although the 369 derivative calculations were made using data from the spectral range $300-725 \mathrm{~nm}$, our results 370 from the derivative analysis for absorption will be reported between the wavelengths of $\lambda_{\min }=$ $371309 \mathrm{~nm}(\equiv 300+9)$ and $\lambda_{\max }=716 \mathrm{~nm}(\equiv 725-9)$. For the reflectance derivative, the results 372 will be reported between $\lambda_{\min }=327 \mathrm{~nm}(\equiv 300+27)$ and $\lambda_{\max }=698 \mathrm{~nm}(\equiv 725-27)$.

373 With regard to the analysis of remote-sensing reflectance, the cluster analysis was also 374 applied to the multispectral reflectance data obtained from in situ SPMR measurements at 375 several discrete wavelengths. We examined the 3 -element objects $\left\{R_{r s}(443) / R_{r s}(554)\right.$, $\left.376 R_{r s}(490) / R_{r s}(554), R_{r s}(510) / R_{r s}(554)\right\}$, which consist of band ratios that are similar to those used 377 in current research based on satellite ocean color observations such as the Sea-viewing Wide 378 Field-of-View Sensor (SeaWiFS). We also examined the vectors consisting of 13 band ratios of 379 remote-sensing reflectance with $R_{r s}(554)$ in the denominator, as determined from SPMR 380 measurements at 13 wavebands.

381 The HCA method, schematically presented in Fig. 3, was applied using the above defined 382 pigment and optical data vectors as input objects. This method utilizes an unsupervised 
383 classification algorithm which creates a hierarchical cluster tree (dendrogram) that partitions a

384 given set of input data into clusters or groups of objects (Jain et al., 1999; Berkhin, 2006). Each

385 group includes objects that are similar to each other, but different from objects in other groups.

386 The cluster tree is obtained using a linkage algorithm based on initial calculations of the

387 pairwise distance between all objects included in the input data set. In this study the similarity

388 between each pair of objects was the cosine distance, $d$, calculated as one minus the cosine of the

389 angle $\theta$ between each pair of objects:

390

$$
d\left(x_{1}, x_{2}\right)=1-\cos \theta=1-\left(\frac{x_{1} \cdot x_{2}}{\left\|x_{1}\right\| \times\left\|x_{2}\right\|}\right)
$$

391 where the objects $x_{1}$ and $x_{2}$ include the two considered input data vectors and the cosine of the 392 angle between the vectors is obtained as the ratio of the dot product of the vectors to the product

393 of norms of the vectors. Note that as the angle between the objects decreases the cosine

394 approaches 1, resulting in a smaller distance between the input data vectors and therefore higher 395 similarity. We also tested other measures of similarity between the input objects, e.g., Euclidean 396 distance using a similar approach to that proposed in Robila (2005). The cosine distance was 397 selected as the most appropriate measure for our study because it reflects mainly the differences 398 in the spectral shape of optical data rather than magnitude. The cosine distance is also 399 advantageous because it is scale invariant, i.e., insensitive to normalization of optical spectra at a 400 specific wavelength.

401 As a linkage algorithm, the shortest distance $D$, also referred to as the nearest neighbor, was 402 computed to measure the distance between two clusters of objects in the tree:

$$
D(a, b)=\min \left[\operatorname{dist}\left(x_{a i}, x_{b j}\right)\right\rfloor \quad i \in\left(1, \ldots, n_{a}\right) \text { and } j \in\left(1, \ldots, n_{b}\right)
$$

404 where $x_{a i}$ is the $i$ th object in cluster $a$ and $x_{b j}$ is the $j$ th object in cluster $b$. In the traditional 405 graphical representation of a dendrogram, the individual objects appear at one end and a single 406 cluster containing all objects at the other end (e.g., Jain et al., 1999). In our presentation of 
407 dendrograms, pairs of objects showing a small cosine distance between them (i.e., with similar

408 pigment composition or spectral properties) provide small linkage distance and therefore appear 409 closer to each other in the cluster tree.

410 To evaluate the utility of optical data for discriminating phytoplankton pigment assemblages, 411 we compared the dendrograms obtained for the different spectral optical data with a reference 412 dendrogram obtained using the pigment composition data (see final step in Fig. 3). For this 413 analysis, we utilize two objective criteria of cluster similarity, the cophenetic index (Sokal \& 414 Rolf, 1962) and the Rand index (Rand, 1971).

415 The cophenetic index $\left(r_{C}\right)$ is a measure of how precisely two dendrograms preserve the 416 pairwise distances between data objects. This index is computed from the cophenetic matrix $(C)$ 417 associated with each dendrogram. The elements of a cophenetic matrix $\left(c_{i, j}\right)$ encode the distance 418 between two objects $(i, j)$, representing in the dendrogram the height of the link at which those 419 two objects are first joined. This height is the distance between the two clusters that are merged 420 by this link. The cophenetic index $r_{C}$ represents the correlation between two cophenetic 421 matrices $\left(C_{1}\right.$ and $\left.C_{2}\right)$ :

$$
r_{C}=\frac{\sum_{i} \sum_{j}\left(c_{1_{i, j}}-\overline{c_{1}}\right)\left(c_{2_{i, j}}-\overline{c_{2}}\right)}{\sqrt{\left(\sum_{i} \sum_{j}\left(c_{1_{i, j}}-\overline{c_{1}}\right)^{2}\right)\left(\sum_{i} \sum_{j}\left(c_{2_{i, j}}-\overline{c_{2}}\right)^{2}\right)}}
$$

423 where $\overline{c_{1}}$ and $\overline{c_{2}}$ are the mean values of the elements of the matrices $C_{1}$ and $C_{2}$, respectively.

424 The Rand index $\left(r_{I}\right)$ provides a measure of the similarity between two hierarchical 425 dendrograms in terms of the proportion of pairs of objects whose relationship is the same in both 426 dendrograms. The $r_{I}$ value of 1 means that all pairs of objects are clustered in the same way in 427 both dendrograms. Note that this index has to be computed using all dendrograms cut 428 horizontally at a level (i.e., at a specific linkage distance) which yields the optimal number of 429 clusters $(k)$. Otherwise, $r_{I}$ would always provide a proportion of $100 \%$ because a complete 430 dendrogram always decomposes the input data all the way through the lowest level (i.e., until the 
431 branches consist only of single objects). Detecting natural groupings in the dendrogram and

432 selecting the optimal number of clusters is performed by analyzing a diagram of the increasing

433 linkage distances along the dendrogram. Based on the points at which the linkage distances

434 between the objects change abruptly (which is associated with a steep increase of the within

435 cluster variance), the optimal number of clusters $k$ is determined and all objects located below

436 the point where the hierarchical tree is cut off are assigned to a single cluster (Salvador \& Chan,

437 2004).

438

\section{3. Results and discussion}

\subsection{Classification of stations based on pigment composition}

442 For the 9 stations selected in the study, the estimate of the TChla concentration ranges from 443 about $0.11 \mathrm{mg} \mathrm{m}^{-3}$ at the southernmost station 59 in the open ocean off the coast of Namibia to $4440.62 \mathrm{mg} \mathrm{m}^{-3}$ at the northernmost station 1 in the English Channel (Fig. 1). The variability in 445 pigment composition for the 9 stations is summarized in Table 1, which provides the ratios of the 446 concentration of several dominant pigments to TChla. Apart from MVChla, which is a principal 447 pigment common to all phytoplankton, the second most important pigment at different stations 448 was either DVChla, zeaxanthin (Zea), 19'-hexanoyloxyfucoxanthin (Hex), or fucoxanthin 449 (Fuco). Table 1 also identifies the two dominant pigments (excluding MVChl $a$ ) which yield the 450 highest ratio to TChl $a$ at each station. The values for the ratios of the two dominant pigments to 451 TChl $a$ were used as a basis for selecting the 9 stations. As these stations represent different 452 pigment compositions, we assigned a class label A, B, C, D, E, or F to each station.

453 Most stations visited during the cruise within the tropical and subtropical regions of the 454 Atlantic were dominated by Zea and DVChla, but the relative predominance of these two 455 pigments varied between the stations. These pigments are diagnostic of picophytoplankton that 
456 include DVChl $a$ - and Zea-containing prochlorophytes and Zea-containing cyanobacteria (mainly

457 Synechococcus in the open ocean waters). We selected 5 stations $(6,12,37,44$, and 46) to

458 represent this type of pigment assemblage. Note that 4 stations dominated by Zea and DVChla

459 with fairly similar ratios DVChl $a / \mathrm{TChl} a$ and Zea/Chl $a$ are grouped within the same class C with

460 a label C1, C2, C3, and C4. The station 6, where DVChla/TChla is significantly higher than

461 Zea/TChla, is considered as a separate class B. This station (or class B) is dominated by

462 prochlorophytes as DVChla is an unambiguous marker of this group. The class C stations also

463 show significant role of prochlorophytes. However, this class exhibits a relatively higher

464 contribution of Zea than class B, which is likely indicative of an increased role of cyanobacteria.

$465 \quad$ Fuco and MVChl $b$ are the predominant accessory pigments at station 1 (class A). As these

466 two pigments are not confined to one phytoplankton class, this station could have been

467 dominated by Fuco-rich diatoms, haptophytes, and/or dinoflagellates, as well as MVChlb-rich

468 prasinophytes and/or chlorophytes. The predominant accessory pigment at stations 48 (class D)

469 and 51 (class E) is Hex, which suggests that haptophytes and/or chrysophytes are major

470 phytoplankton groups at these locations. These stations are designated as different classes

471 because they clearly differ in accessory pigments that follow Hex in ranking. Zea and Fuco are

472 the second most important diagnostic pigments at stations 48 (class D) and 51 (class E),

473 respectively. Finally, station 59 (class F) also shows a significant role of Hex-rich phytoplankton

474 although Zea is the most important diagnostic pigment at this location, indicating potential

475 significance of cyanobacteria and/or prochlorophytes.

476 Fig. 4a shows the hierarchical cluster tree obtained for the input data consisting of the ratios

477 of concentrations of 24 individual pigments to TChla at each station. The optimal number of

478 clusters $(k)$ is derived from a diagram of linkage distances along the dendrogram (Fig. 4b). The

479 first steep increase in the linkage distance observed in this diagram, which is associated with an

480 increase of the within cluster variance, suggests an optimal partitioning of the pigment data into

4815 clusters. The linkage distance of 0.023 can be selected to characterize this steep increase in 
variance (see dashed lines in Fig. $4 \mathrm{a}$ and $4 \mathrm{~b}$ ). For the dendrogram cut at a level of linkage

483 distance of 0.023 , all clusters are single object (i.e., single station) clusters, except for a multi-

484 object cluster that includes stations C1, C2, C3, C4, and B. The results of this cluster analysis

485 are quite consistent with the preliminary classification obtained by considering just two dominant

486 diagnostic pigments (see Table 1). Note that stations C1, C2, C3, C4, and B are all characterized

487 by relatively high ratios of DVChla and Zea to TChl $a$. Some differences between these stations

488 in terms of the relative roles of DVChl $a$ and Zea do not, however, produce significant distances

489 between the corresponding pigment data vectors and hence these 5 stations are grouped into a

490 single cluster. The dendrogram also indicates that the stations classified as A, D, E, and F

491 display significant dissimilarities between each other and when compared to the stations

492 classified as B and C. Note that the stations 48 (class D) and 59 (class F) have the Hex and Zea

493 as dominant diagnostic pigments, albeit in reverse ranking (see Table 1), so these stations appear

494 closer to one another in the dendrogram (Fig. 4a).

495 Fig. 4c also depicts results from the cluster analysis of pigment data but for the input data

496 vectors consisting of the ratios of concentrations of the 8 diagnostic pigments to the sum of the 8

497 diagnostic pigments. The partitioning of the stations obtained on the basis of these pigment

498 ratios is qualitatively identical to the partitioning based on the ratios of 24 pigments to TChl $a$.

499 The stations C1, C2, C3, C4, and B are again grouped within a single cluster and each of the

500 remaining stations represent a separate cluster. The results in Figs. 4a and 4c along with the

501 preliminary classification of stations based on two dominant diagnostic pigments (Table 1)

502 suggest that there is a certain degree of flexibility in the selection of pigment ratios as a basis for

503 discriminating different pigment assemblages in a consistent fashion. In the following analysis

504 of optical data as a means for assessing differences in pigment assemblages, the pigment-based

505 cluster partitioning obtained with the 24 pigment ratios (as shown in Fig. 4a) is used as a

506 reference. 


\subsection{Classification of stations based on absorption spectra}

$509 \quad$ Fig. 5 shows hyperspectral data of absorption coefficients first normalized at $555 \mathrm{~nm}$ and 510 then divided by the total chlorophyll- $a$ concentration for the nine stations. These spectra are

511 referred to as the spectral chlorophyll (Chl)-specific normalized absorption coefficients.

512 Specifically, we examine the Chl-specific normalized coefficients for the total absorption, $a_{n} *(\lambda)$,

513 the absorption of pure seawater plus phytoplankton, $a_{n, w+p h} *(\lambda)$, and the absorption of

514 phytoplankton alone, $a_{n, p h} *(\lambda)$. The differences in the shape of phytoplankton absorption in the

515 UV and blue spectral regions are generally quite large between most stations (Fig. 5a). With the

516 addition of the pure water contribution, differences in the spectral shape of $a_{n, w+p h} *(\lambda)$ continue

517 to be seen but are considerably smaller (Fig. 5b). Finally, upon further addition of the

518 contributions associated with non-phytoplankton particles and CDOM, the spectral shape of total

519 absorption again shows larger differences between the stations at wavelengths shorter than the

520 normalization point at $555 \mathrm{~nm}$ (Fig. 5c). From the visual inspection of these plots it is, however,

521 difficult to deduce to what extent the observed differences might be consistent with the

522 classification of stations based on pigment composition.

523 Fig. 6 illustrates the results from cluster analysis applied to the absorption spectra presented

524 in Fig. 5 and the corresponding second derivative spectra over the entire spectral range from 300

$525 \mathrm{~nm}$ to $725 \mathrm{~nm}$. In nearly all cases (Fig. 6a-e), the absorption-based cluster trees differ

526 significantly from the pigment-based cluster tree shown in Fig. 4a. Thus, the full hyperspectral

527 data of $a_{n}^{*}(\lambda), a_{n, w+p h} *(\lambda)$, and $a_{n, p h} *(\lambda)$ as well the second derivative spectra of $a_{n} *(\lambda)$ and

$528 a_{n, w+p h} *(\lambda)$ do not provide useful information for discriminating the differences in pigment

529 assemblages at the examined stations. The only case in which stations are classified within the

530 dendrogram in a similar way to the pigment-based cluster tree is when the second derivative of

531 phytoplankton absorption spectra is considered (Fig. 6f). When this absorption-based

532 dendrogram is cut horizontally at a level of linkage distance of 0.023 that yields 5 clusters, the 
533 same stations are grouped in separate clusters as in the pigment-based cluster tree. This result

534 supports the potential usefulness of the second derivative of phytoplankton absorption spectra for 535 discriminating different pigment assemblages.

536 In the analysis above we considered a spectral range from $300 \mathrm{~nm}$ to $725 \mathrm{~nm}$, which is much

537 broader than the spectral region where specific absorption imprints caused by accessory

538 pigments occur. It is therefore useful to examine whether the cluster analysis of absorption data

539 yields similarity with pigment-based clusters if different, narrower spectral ranges are

540 considered. Fig. 7 illustrates the degree of similarity between the absorption-based and pigment-

541 based cluster trees for different spectral ranges of absorption data. The degree of similarity is

542 shown in terms of cophenetic and Rand indices. The three absorption spectra, $a_{n} *(\lambda)$,

$543 a_{n, w+p h} *(\lambda)$, and $a_{n, p h} *(\lambda)$, are considered in this analysis. In each graph, the distribution of

544 values for the cophenetic or Rand index is shown as a function of the spectral range considered,

545 with the lower limit of the spectral range, $\lambda_{\min }$, displayed along the $y$-axis (ordinate) and the

546 upper limit, $\lambda_{\max }$, along the $\mathrm{x}$-axis (abscissa). The similarity indices are thus shown for many

547 spectral ranges represented by many combinations of $\lambda_{\min }$ and $\lambda_{\max }$. The higher values of indices,

548 depicted by darker areas in the graphs, correspond to better similarity between a given

549 absorption-based cluster tree and pigment-based tree. The best degree of similarity is obtained

550 when the indices are close to 1 , indicated by the nearly black areas in the graphs. According to

551 the distributions of cophenetic index, this is the case when the phytoplankton absorption

552 spectrum $a_{n, p h} *(\lambda)$ is analyzed over the spectral range approximately from $\lambda_{\min }=425 \mathrm{~nm}$ to $\lambda_{\max }$

$553=540 \mathrm{~nm}$ (Fig. 7e). The distribution of the Rand index indicates that the best similarity between

554 the $a_{n, p h} *(\lambda)$-based cluster tree and the pigment-based tree occurs within a broader spectral

555 region, approximately between $\lambda_{\min }=390 \mathrm{~nm}$ and $\lambda_{\max }=610 \mathrm{~nm}$ (Fig. 7f). These optimal

556 spectral regions generally overlap with the wavelength range where absorption characteristics of

557 main accessory pigments appear (e.g., Bricaud et al., 2004). The remaining results in Fig. 7 
558 (panels a, b, c, d) show generally poor similarity between the absorption data of $a_{n} *(\lambda)$ or $559 a_{n, w+p h} *(\lambda)$ and pigment composition, regardless of the spectral range considered.

560 Fig. 8 depicts similar results, but for the similarity between pigment composition and the 561 second derivative spectra of $a_{n}{ }^{*}(\lambda), a_{n, w+p h} *(\lambda)$, and $a_{n, p h} *(\lambda)$. The use of derivative spectra 562 generally improves the similarity as indicated by the presence of darker areas or the larger extent 563 of dark areas in the distributions of the cophenetic and Rand indices. For example, compared to 564 the results for the ordinary spectra of $a_{n, w+p h} *(\lambda)$ in Fig. 7d, a significant increase in the Rand 565 index is observed for the second derivative spectra of $a_{n, w+p h} *(\lambda)$ within the spectral range from $566 \lambda_{\min }=440 \mathrm{~nm}$ to $\lambda_{\max }=650 \mathrm{~nm}$ (Fig. 8d). The improvement is even more striking for the results 567 involving the second derivative spectra of phytoplankton absorption (Fig. 8e, f). The spectral 568 regions where the cophenetic and Rand indices assume high values near or equal to 1 are much 569 larger compared with the analysis of ordinary (non-differentiated) spectra of $a_{n, p h} *(\lambda)$. The 570 darkest areas in the distributions of the indices in Fig. 8e, $\mathrm{f}$ cover a broad spectral range, 571 approximately from $\lambda_{\min }=370 \mathrm{~nm}$ to $\lambda_{\max }=716 \mathrm{~nm}$. This result indicates that a high degree of 572 similarity between the second derivative spectra of $a_{n, p h} *(\lambda)$ and pigment composition can be 573 obtained for many different combinations of spectral ranges of absorption data (i.e., different 574 combinations of $\lambda_{\min }$ and $\left.\lambda_{\max }\right)$.

575 The improvement in the similarity between the pigment-based and absorption-based cluster 576 trees achieved as a result of utilization of second derivative spectra compared to the ordinary 577 spectra of phytoplankton absorption, $a_{n, p h} *(\lambda)$, is clearly illustrated by histograms of cophenetic 578 index obtained on the basis of all possible combinations of spectral ranges examined (Fig. 9). 579 We note that the cophenetic index does not require a priori selection of the optimal number of 580 clusters which is somewhat subjective and, therefore, this index facilitates the comparison of 581 results for ordinary and derivative spectra shown in Fig. 7e and Fig. 8e. Compared with the 582 histogram obtained using the ordinary spectra (Fig. 9a), the histogram for the derivative spectra 583 (Fig. 9b) shows a substantial shift to higher values of the cophenetic index. Specifically, there is 
584 a significant increase in the frequency of occurrence of high values (>0.9) of the cophenetic

585 index. This increased frequency is associated with a broader overall spectral region, or

586 equivalently a larger number of spectral ranges, for which the index is higher than 0.9.

587 Whereas the above results illustrate the advantages of derivative analysis, such analysis can

588 be highly sensitive to parameters chosen for the calculation of derivative spectra, specifically the 589 size of the filter window (WS) used in the spectral smoothing of the ordinary spectra and the 590 band separation $(B S)$ used in the calculation of derivatives. To examine the sensitivity of cluster 591 analysis to the selection of these parameters, we computed the distribution of cophenetic index 592 between the pigment-based and absorption-based cluster trees using the second derivative 593 spectra of $a_{n, p h} *(\lambda)$ within the spectral range of $420-515 \mathrm{~nm}$ as input (Fig. 10). This spectral 594 range is adequate for this sensitivity analysis because it showed very high values of cophenetic 595 and Rand indices in Fig. 7e and Fig. 8e. The distribution of cophenetic index in Fig. 10 is shown 596 with the smoothing parameter WS varying from 1 to 29 consecutive samples (with a step of 2 597 samples) along the y-axis and the band separation parameter $B S$ varying also from 1 to 29 598 samples with a step of 2 samples along the $\mathrm{x}$-axis. Note that the number of consecutive samples 599 is equivalent to the wavelength interval in nanometers because our spectral data (samples) have 600 the resolution of $1 \mathrm{~nm}$. The highest values of the cophenetic index are obtained for intermediate 601 values of $W S$ and $B S$ around $9 \mathrm{~nm}-10 \mathrm{~nm}$. These are the optimal values for our derivative 602 analysis of absorption spectra. This result is consistent with the general expectation that if the 603 values of $W S$ and $B S$ are too small, the derivative spectra are sensitive to noise and exhibit false 604 spectral features, and on the other hand if the WS and $B S$ are too large, the real significant 605 spectral features get smoothed out and essentially removed from the analysis. As the best 606 compromise, the cluster analyses presented in Fig. 8 and $9 \mathrm{~b}$ were obtained with WS and $B S$ of 9 $607 \mathrm{~nm}$. 


\subsection{Classification of stations based on remote-sensing reflectance}

610 The relationship between the spectral remote-sensing reflectance, $R_{r s}(\lambda)$, of the ocean and 611 phytoplankton pigment composition is less direct and far more complicated than that for the

612 spectral phytoplankton absorption coefficient, mainly due to the presence of many optically

613 significant non-phytoplankton constituents in seawater. The investigation of $R_{r s}(\lambda)$ is of

614 particular interest, however, because information contained in this measurement provides a

615 potential means for remote-sensing applications. Fig. 11 shows the Hydrolight-simulated $R_{r s}(\lambda)$

616 spectra normalized at $555 \mathrm{~nm}$ for the nine stations identified as classes from A (station 1) through

$617 \mathrm{~F}$ (station 59). In general, there are significant differences in the UV and blue spectral regions

618 between these normalized spectra, with the largest contrast between the classes A (station 1) and

619 C1 (station 12).

620 The dendrograms obtained from cluster analysis as applied to four different sets of input data

621 vectors containing information about remote-sensing reflectance (as described in sec 2.3) are

622 displayed in Fig. 12. The limited spectral information, i.e., the three reflectance band ratios used

623 commonly in satellite ocean color applications (Fig. 12a) and the 13 band ratios corresponding to

624 multispectral measurements with the SPMR instrument (Fig. 12b), provide a very dissimilar

625 classification of stations compared with the pigment-based cluster analysis (see Fig. 4a). All

626 stations, with only the exception of class A, show very little separation in the cluster-tree based

627 on multispectral reflectance data. The high spectral resolution $(1 \mathrm{~nm})$ normalized reflectance

628 spectra over the entire spectral range $300-725 \mathrm{~nm}$ also produce a dendrogram (Fig. 12c) that is

629 very different from the pigment-based cluster tree. Although the stations belonging to class $\mathrm{C}$

630 are closer to one another compared with the multispectral-based cluster tree, they are grouped

631 together with two other stations (class E and D). In addition, station B forms a separate single-

632 object cluster in Fig. 12c, whereas it is grouped in a single multi-object cluster together with the

633 stations from class $\mathrm{C}$ in the pigment analysis. The only case when the cluster analysis of

634 reflectance data provides a high degree of similarity with pigment analysis (i.e., Rand index of 
635 0.78) is for the second derivative of hyperspectral normalized reflectance over the entire spectral

636 range $327-698 \mathrm{~nm}$ (Fig. 12d). We note that the derivative reflectance spectra were calculated

637 with the parameters $W S$ and $B S$ of $27 \mathrm{~nm}$ (as supported by the sensitivity analysis discussed

638 below). The stations A, E, and F in Fig. 12d form single-object clusters at a significant distance

639 from the remaining stations. Similarly to pigment analysis, the stations C1, C2, C3, C4, and B

640 are grouped relatively close to one another. However, station D also belongs to that group,

641 which is not the case in the pigment-based cluster tree. This may be attributable to the fact that

642 Zea and DVChla, which are the two most dominant diagnostic pigments at stations C1, C2, C3,

$643 \mathrm{C} 4$, and B, also play a significant role at station D where they are ranked as the second and third

644 most important diagnostic pigments (see Table 1).

645 The progression of linkage distances corresponding to the four dendrograms from Fig. 12

646 clearly illustrates the advantage of the second derivative spectra over the multispectral data or

647 non-differentiated spectra of reflectance (Fig. 13). The improved separation seen in terms of the

648 larger linkage distances between the clusters of stations obtained with derivative spectra

649 indicates that this approach enables better identification of the differences in the magnitude and

650 shape between the high resolution spectra. In contrast, in the analysis of multispectral data and

651 ordinary spectra, stations are linked at a very small distance, which indicates that these types of

652 reflectance data will be essentially useless for obtaining information about pigment assemblages

653 from cluster analysis.

654 The improvement in the similarity between the pigment-based and reflectance-based

655 classification achieved with the use of second derivative spectra as opposed to multispectral data

656 or ordinary spectra of reflectance is presented in Table 2. The results for the derivative analysis

657 of hyperspectral normalized $R_{r s}(\lambda)$ over the entire spectral range $300-725 \mathrm{~nm}$ show a significant

658 increase in both the cophenetic and Rand index when compared with multispectral and ordinary

659 spectral data. However, the best performance is obtained when the derivative analysis is 
660 restricted to the spectral range from 435 to $495 \mathrm{~nm}$ (as supported by the sensitivity analysis

661 discussed below). In this case, the similarity indices are highest.

662 Fig. 14 shows distributions of the cophenetic and Rand index which identify the optimal 663 spectral ranges for the cluster analysis of the second derivative of remote-sensing reflectance.

664 The cophenetic index is generally close or slightly higher than 0.5 for most spectral ranges 665 examined, that is for most combinations of $\lambda_{\min }$ and $\lambda_{\max }$ (Fig. 14a). In the spectral region from $666435 \mathrm{~nm}$ to $510 \mathrm{~nm}$, this index is about 0.65 . This can be considered as an optimal spectral range

667 for the application of derivative approach with potential for good similarity between the 668 pigment-based and reflectance-based cluster trees. This result is also supported by very high 669 value of the Rand index of 0.86 in that spectral range (Fig. 14b). The Rand index attains even 670 higher value of about 1 within somewhat narrower wavelength range from $\lambda_{\min }=435 \mathrm{~nm}$ to $\lambda_{\max }$ $671=495 \mathrm{~nm}$, which defines an alternative optimal spectral range. In addition, the Rand index 672 suggests good performance of the derivative-based analysis over a broader spectral region 673 including shorter wavelengths of $\lambda_{\min }$ from the near-UV. In general, this index is quite high for $674 \lambda_{\min }$ varying between $350 \mathrm{~nm}$ and $450 \mathrm{~nm}$, for example as high as 1 when the spectral range is 675 from $\lambda_{\min }=365 \mathrm{~nm}$ to $\lambda_{\max }=480 \mathrm{~nm}$. However, because the optical roles of different diagnostic 676 pigments in the near-UV are insignificant or certainly less important than in the blue region, the 677 use of the spectral range $435-510 \mathrm{~nm}$ or $435-495 \mathrm{~nm}$, where both the cophenetic and Rand 678 indices are relatively high, appears to be most reasonable.

679 The effects of the size of the filter window (WS) used in the smoothing of the ordinary 680 spectra and the band separation $(B S)$ used in the calculation of derivatives on the similarity 681 between the cluster trees from the analysis of pigments and the second derivative reflectance 682 spectra is illustrated in Fig. 15. These results are shown for the derivative spectra calculated over 683 one of the optimal spectral ranges, specifically $435-495 \mathrm{~nm}$, which showed high values for both 684 cophenetic and Rand indices. The best similarity with cophenetic index of about 0.65 and the 685 Rand index of 1 is obtained when the calculations of second derivative spectra are made with 
686 relatively large values of $W S$ and $B S$. For example, a very good result is obtained if both $W S$ and

$687 B S$ assume a value of 27 consecutive spectral samples (i.e., $27 \mathrm{~nm}$ as the resolution of our

688 hyperspectral reflectance data is $1 \mathrm{~nm}$ ). We recall that this value was used to compute the results

689 pertinent to the derivative reflectance spectra presented in Figs. 12 - 14. Similarly good results

690 are obtained with a smaller $W S(\sim 14 \mathrm{~nm})$ and a larger $B S(\sim 37 \mathrm{~nm})$, or vice versa. In contrast, if

691 both $W S$ and $B S$ are small (less than about $10 \mathrm{~nm}$ ) or large (above $\sim 40 \mathrm{~nm}$ ) the cophenetic and

692 Rand indices are reduced significantly. This sensitivity analysis, in agreement with similar

693 analysis for absorption spectra, supports strong dependence of the derivative-based cluster trees

694 on the selection of parameters $W S$ and $B S$ for the derivative calculations.

\section{Conclusions}

697 By applying the unsupervised hierarchical cluster analysis to pigment and optical data from

698 the eastern Atlantic Ocean we demonstrated the potential usefulness of hyperspectral data of

699 absorption coefficient and remote-sensing reflectance for discriminating different phytoplankton

700 pigment assemblages in the open ocean under non-bloom conditions. The most promising

701 results were obtained with the second derivative spectra of phytoplankton absorption coefficient

702 covering the spectral range as wide as $370 \mathrm{~nm}-725 \mathrm{~nm}$ (or narrower spectral regions from

703 within that range), and the second derivative spectra of remote-sensing reflectance over the

704 spectral range from about $435 \mathrm{~nm}$ to $510 \mathrm{~nm}$. Our ability to discriminate different phytoplankton

705 pigment assemblages from the derivative-based cluster trees was optimized by selecting the most

706 suitable parameters used in the spectral derivative calculations (see also Torrecilla et al., 2009).

707 In particular, for these optical data with a $1 \mathrm{~nm}$ resolution, we determined that the optimal values

708 for the smoothing filter window and band separation used in the calculations of second derivative

709 spectra are $9 \mathrm{~nm}$ for absorption and $27 \mathrm{~nm}$ for remote-sensing reflectance. These derivative

710 spectra are presented in Fig. 16 for the nine Atlantic stations selected for this study. The 
711 assessment of similarity between these derivative spectra and phytoplankton pigment

712 composition was made using the similarity-based cluster algorithm and two indices, cophenetic

713 and Rand. In this cluster algorithm, the partitioning of data into clusters is based on the

714 determinations of the angular distance between each pair of examined input data vectors. This

715 type of similarity-based cluster technique accounts for complete spectral behavior of optical data

716 with no need to identify specific spectral features. This approach is particularly useful in cases

717 when it is difficult or impossible to define explicitly a set of unambiguous diagnostic spectral

718 features in the original optical data (Duin et al., 1997; Pekalska and Duin, 2000).

719 In addition to the second derivative spectra of phytoplankton absorption and remote-sensing

720 reflectance, we examined other absorption and reflectance data but they generally showed either

721 more limited value or no usefulness at all for discriminating phytoplankton pigment

722 assemblages. For example, the cluster analysis of the ordinary (non-differentiated) reflectance

723 spectra at $1 \mathrm{~nm}$ resolution or multispectral (13 wavebands) reflectance data showed very poor

724 similarity with pigment-based clusters. Similar results were obtained for the ordinary spectra of

725 the total absorption coefficient. However, the ordinary spectra of phytoplankton absorption are

726 useful, especially within the spectral range $425 \mathrm{~nm}-540 \mathrm{~nm}$.

727 We demonstrated that the quantification of similarity between the optical-based clusters and 728 pigment-based clusters with the cophenetic and Rand indices provides a valuable methodology

729 for identifying optical variables and their spectral ranges most suitable for characterizing the

730 phytoplankton pigment assemblages, and for selecting the optimal values of the parameters used

731 in the calculation of derivative spectra. Whereas the present study uses a limited data set, albeit

732 carefully selected to represent distinct differences in phytoplankton assemblages in terms of

733 dominant accessory pigments, further work is needed to evaluate or refine the proposed

734 methodology with larger data sets from various oceanic environments. Given significant interest

735 in the development of the capabilities for large-scale characterization of phytoplankton

736 biodiversity from optical measurements including remote-sensing observations, one may expect 
737 further expansion of comprehensive databases consisting of simultaneously collected pigment

738 and hyperspectral optical data in the near future. We expect that this will support further work on

739 the cluster-based approach and other techniques, such as neural networks (Raitsos et al., 2008;

740 Aymerich et al., 2009), which exploit optical measurements as a source of information on

741 phytoplankton community composition.

\section{Acknowledgements}

744 This study was supported by the NASA Biodiversity and Ecological Forecasting Program (Grant

745 NNX09AK17G), the NASA Ocean Biology and Biogeochemistry Program (Grant

746 NNG04GO02G), and the Spanish National Research Council CSIC (project ANERIS PIF08-

747 015). Part of this study was performed during a visit of E. T. at Scripps Institution of

748 Oceanography supported also by CSIC (Program I3P). The Alfred Wegener Institute for Polar

749 and Marine Research (Bremerhaven, Germany) kindly made it possible for us to participate in

750 the cruise in the eastern Atlantic. We thank R. Röttgers for providing PSICAM data and HPLC

751 data from analysis at GKKS Research Centre (Geesthacht, Germany).

\section{References}

754 Aiken, J., Fishwick, J. R., Lavender, S. J., Barlow, R., Moore, G., Sessions, H., et al. (2007).

755 Validation of MERIS reflectance and chlorophyll during the BENCAL cruise October, 2002:

756 Preliminary validation of new products for phytoplankton functional types and

757 photosynthetic parameters. International Journal of Remote Sensing, 28, 497-516.

758 Alvain, S., Moulin, C., Dandonneau, Y., \& Bréon, F. M. (2005). Remote sensing of

759 phytoplankton groups in case 1 waters from global SeaWiFS imagery. Deep-Sea Research I, $760 \quad 52,1989-2004$.

761 Aymerich, I. F., Piera, J., Soria-Frisch, A., \& Cros, Ll. (2009). A rapid technique for classifying 
phytoplankton fluorescence spectra based on self-organizing maps. Applied Spectroscopy, 63, 716-726.

Balch, W. M., Gordon, H. R., Bowler, B. C., Drapeau, D. T., \& Booth, E. S. (2005). Calcium carbonate measurements in the surface global ocean based on Moderate-Resolution Imaging Spectroradiometer data. Journal of Geophysical Research, 110, C07001, doi:10.1029/2004JC002560.

Berkhin, P. (2006). A Survey of Clustering Data Mining Techniques. In J. Kogan, C. Nicholas and M. Teboulle (Eds.), Grouping multidimensional data: Recent advances in clustering (pp. 25-71). Berlin-Heidelberg: Springer.

Bricaud, A., Morel, A., Babin, M., Allali, K., \& Claustre, H. (1998). Variations of light absorption by suspended particles with chlorophyll- $a$ concentration in oceanic (case 1)

waters: Analysis and implications for bio-optical models. Journal of Geophysical Research, $103,31033-31044$.

Bricaud, A., Claustre, H., Ras, J., \& Oubelkheir, K. (2004). Natural variability of phytoplankton absorption in oceanic waters: influence of the size structure of algal population. Journal of Geophysical Research, 109, C11010, doi:10.1029/2004JC002419.

Buiteveld, H., Hakvoort, J. H. M., \& Donze, M. (1994). The optical properties of pure water. In J. S. Jaffe (Ed.), Ocean Optics XII, Proc. SPIE, 2258 (pp. 174-183). Bellingham: SPIE.

Chang, G. C., Mahoney, K., Briggs-Whitmire, A., Kohler, D., Mobley, C., Moline, M., Lewis, M., Boss, E., Kim, M., Philpot, W., \& Dickey, T. (2004). The New Age of Hyperspectral Oceanography. Oceanography, 17(2), 22-29.

Chang, G. C., Dickey, T., \& Lewis, M. (2006). Toward a global ocean system for measurements of optical properties using remote sensing and in situ observations. In J. Gower (Ed.), Remote Sensing of the Marine Environment: Manual of Remote Sensing (pp. 285-326). New York: John Wiley and Sons.

Ciotti, A. M., \& Bricaud, A. (2006). Retrievals of a size parameter for phytoplankton and spectral 
light absorption by colored detrital matter from water-leaving radiances at SeaWiFS channels in a continental shelf region off Brazil. Limnology and Oceanography: Methods, 4, 237-253.

Craig, S. E., Lohrenz, S. E., Lee, Z., Mahoney, K. L., Kirkpatrick, G. J., Schofield, O. M., \&

791 Steward, R. G. (2006). Use of hyperspectral remote sensing reflectance for detection and 792 assessment of the harmful alga, Karenia brevis. Applied Optics, 45, 5414-5425.

793 Cullen, J. J., Ciotti, A. M., Davis, R. F., \& Lewis, M. R. (1997). Optical detection and assessment 794 of algal blooms. Limnology and Oceanography, 42, 1223-1239.

795 Dickey, T., Lewis, M., \& Chang, G. (2006). Optical oceanography: recent advances and future 796 directions using global remote sensing and in situ observations. Reviews of Geophysics, 44, 797 RG1001, 1-39.

798 Duin, R. P. W., de Ridder, D., \& Tax, D. M. J. (1997). Experiments with a featureless approach to 799 pattern recognition. Pattern Recognition Letters, 18, 1159-1166.

800 Ferrari, G. M., \& Tassan, S. (1999), A method using chemical oxidation to remove light 801 absorption by phytoplankton pigments, Journal of Phycology, 35, 1090-1098.

802 Fry, E. S., Lu, Z., \& Qu, X. (2006), Optical absorption of pure water throughout the visible and 803 near ultraviolet. Proceedings of Ocean Optics Conference XVIII, Montreal, Canada.

804 Hooker, S.B., \& Van Heukelem, L. (2009), CHORS HPLC Uncertainties: Final Report. World 805 Wide Web page, from URL: http://oceancolor.gsfc.nasa.gov/DOCS/ . NASA Goddard Space 806 Flight Center, Greenbelt, Maryland, 62 pp.

807 Hunter, P. D., Tyler, A. N., Présing, M., Kovács, A. W., \& Preston, T. (2008). Spectral 808 discrimination of phytoplankton colour groups: The effect of suspended particulate matter 809 and sensor spectral resolution. Remote Sensing of Environment, 112, 1527-1544.

810 Jain, A. K., Murty, M. N., \& Flynn, P. J. (1999). Data clustering: A review. ACM Computing $811 \quad$ Surveys, 31, 264-323. 
812 Jeffrey, S. W., Wright, S. W., \& Zapata, M. (1997). Recent advances in HPLC pigment analysis

813 of phytoplankton. Marine and Freshwater Research, 50, 879-896.

814 Kostadinov, T. S., Siegel, D. A., \& Maritorena, S. (2009). Retrieval of the particle size

815 distribution from satellite ocean color observations. Journal of Geophysical Research, 114,

816 C09015, doi:10.1029/2009JC005303.

817 Lee, Z., \& Carder, K. L. (2002). Effect of spectral band numbers on the retrieval of water column

818 and bottom properties from ocean color data. Applied Optics, 41, 2191-2201.

819 Lee, Z.P., \& Carder, K.L. (2004). Absorption spectrum of phytoplankton pigments derived from

820 hyperspectral remote-sensing reflectance. Remote Sensing Environment, 89, 361-368.

821 Louchard, E. M., Reid, R. P., Stephens, C. F., Davis, C. O., Leathers, R. A., Downes, T. V., \&

822 Maffione, R. (2002). Derivative Analysis of Absorption Features in Hyperspectral Remote

823 Sensing Data of Carbonate Sediments. Optics Express, 10,1573-1584.

824 Lubac, B., Loisel, H., Guiselin, N., Astoreca, R., Felipe Artigas, L., \& Mériaux, X. (2008).

825 Hyperspectral and multispectral ocean color inversions to detect Phaeocystis globosa blooms

826 in coastal waters. Journal of Geophysical. Research, 113, C06026,

827 doi:10.1029/2007JC004451.

828 Mackey, M. D., Mackey, D. J., Higgins, H. W., \& Wright, S. W. (1996). CHEMTAX - a program

829 for estimating class abundances from chemical markers: Application to HPLC measurements

$830 \quad$ of phytoplankton. Marine Ecology Progress Series, 144, 265-283.

831 Mobley, C. D. (1994). Light and Water: Radiative Transfer in Natural Waters. (pp. 592). San

832 Diego: Academic Press.

833 Mobley, C. D. (2008). Hydrolight Ecolight 5.0 User's Guide. (pp. 99). Mercer Island,

834 Washington: Sequoia Scientific Inc.

835 Morel, A. (1988). Optical modeling of the upper ocean in relation to its biogenous matter content

836 (case I waters), Journal of Geophysical Research, 93, 10749-10768.

837 Mueller, J. L., Fargion, G. S., \& McClain, C. R. Eds. (2003). Ocean Optics Protocols for Satellite 
Ocean Color Sensor Validation, Revision 4, Volume III: Radiometric Measurements and Data Analysis Protocols, NASA/TM-2003-211621/Rev4-Vol. III, 78 pp., NASA Goddard Space Flight Center, Greenbelt, Maryland.

Nair, A., Sathyendranath, S., Platt, T., Morales, J., Stuart, V., Forget, M., Devred, E., \& Bouman, H. (2008). Remote sensing of phytoplankton functional types. Remote Sensing of Environment, 112, 3366-3375.

844 O’Reilly, J. E., Maritorena, S., Siegel, D. A. et al. (2000). Ocean Color chlorophyll-a Algorithms

845 for SeaWiFS, OC2, and OC4: Version 4. SeaWiFS Postlaunch Technical Report Series,

Pekalska, E., \& Duin, R. P. W. (2000). Classifier for dissimilarity-based pattern recognition. Proceedings of the 15th International Conference on Pattern Recognition, 12-16.

Perry, M. J., \& Rudnick, D.L. (2003). Observing the oceans with autonomous and Lagrangian

Pope, R. M., \& Fry, E. S. (1997). Absorption spectrum (380-700nm) of pure water. II. Integrating platforms and sensors: The role of ALPS in sustained ocean observing systems. cavity measurements. Applied Optics, 36, 8710-8723.

Raitsos, D. E., Lavender, S. J., Maravelias, C. D., Haralabous, J. A., Richardson, J., \& Reid, P. (2008). Identifying four phytoplankton functional types from space: An ecological approach, Limnology and Oceanography, 53, 605-613.

Rand, W. M. (1971). Objective criteria for the evaluation of clustering methods. Journal of the American Statistical Association, 66, 846-850.

Reynolds, R. A., Stramski D., \& Mitchell, B. G. (2001). A chlorophyll-dependent semianalytical model derived from field measurements of absorption and backscattering coefficients within the Southern Ocean. Journal of Geophysical Research, 106, 7125-7138. 
863 Robila, S. A. (2005). Using spectral distances for speedup in hyperspectral image processing.

$864 \quad$ International Journal of Remote Sensing, 26:24, 5629 - 5650.

865 Röttgers, R., \& Doerffer, R. (2007). Measurements of optical absorption by chromophoric

866 dissolved organic matter using a point-source integrating-cavity absorption meter. Limnology

867 and Oceanography: Methods, 5, 126-135

868 Röttgers, R., Schönfeld, W., P-R. Kipp, P-R., \& Doerffer, R. (2005), Practical test of a point-

869 source integrating cavity absorption meter: The performance of different collector

$870 \quad$ assemblies. Applied Optics, 44, 5549-5560.

871 Salvador, S., \& Chan, P. (2004). Determining the number of clusters/segments in hierarchical

872 clustering/segmentation algorithms. Proceedings of 16th IEEE International Conference on

$873 \quad$ Tools with AI, 576-584.

874 Sokal, R. R., \& Rohlf, F. J. (1962). The comparison of dendrograms by objective methods.

875 Taxon, 11(2), 33-40.

876 Stramska, M., Stramski, D., Kaczmarek, S., Allison, D. B., \& Schwarz, J. (2006). Seasonal and

877 regional differentiation of bio-optical properties within the north polar Atlantic. Journal of

878 Geophysical Reserach, 111, C08003, doi:10.1029/2005JC003293.

879 Stramski, D., Reynolds, R. A., Babin, M., Kaczmarek, S., Lewis, M. R., Röttgers, R., Sciandra,

880 A., Stramska, M., Twardowski, M. S., Franz, B. A., \& Claustre, H. (2008). Relationships

881 between the surface concentration of particulate organic carbon and optical properties in the

882 eastern South Pacific and eastern Atlantic Oceans. Biogeosciences, 5, 171-201.

883 Stumpf, R. P., Culver, M. E., Tester, P. A., Tomlinson, M., Kirkpatrick, G. J., Pederson, B. A.,

884 Truby, E., Ransibrahmanakul, V., \& Soracco, M. (2003). Monitoring Karenia brevis blooms

885 in the Gulf of Mexico using satellite ocean color imagery and other data. Harmful Algae, 2,

$886 \quad 147-160$.

887 Tassan, S., \& Ferrari, G. M. (1995). An alternative approach to absorption measurements of

888 aquatic particles retained on filters, Limnology and Oceanography, 40, 1358-1368. 
889 Tassan, S., \& Ferrari, G. M. (2002). A sensitivity analysis of the 'Transmittance-Reflectance'

890 method for measuring light absorption by aquatic particles, Journal of Plankton Research, 24,

$891 \quad 757-774$.

892 Torrecilla, E., Piera J., \& Vilaseca, M. (2009). Derivative analysis of oceanographic

893 hyperspectral data. In G. Jedlovec (Ed.), Advances in Geoscience and Remote Sensing (pp.

894 597-619). Vienna: InTech.

895 Tsai, F., \& Philpot, W. D. (1998). Derivative analysis of hyperspectral data. Remote Sensing of

896 Environment, 66, 41-51.

897 Twardowski, M. S., Claustre, H., Freeman, S. A., Stramski, D., \& Huot, Y. ( 2007). Optical

898 backscattering properties of the "clearest" natural waters. Biogeosciences, 4, 1041-1058.

899 Uitz, J., Claustre, H., Gentili, B., \& Stramski, D. (2010). Phytoplankton class-specific primary

900 production in the world's oceans: Seasonal and interannual variability from satellite

901 observations. Global Biogeochemical Cycles, 24, GB3016, doi:10.1029/2009GB003680.

902 Uitz, J., Claustre, H., Morel, A., \& Hooker, S. (2006). Vertical distribution of phytoplankton

903 communities in open-ocean: An assessment based on surface chlorophyll. Journal of

904 Geophysical Research, 111, CO8005, doi:10.1029/2005JC003207.

905 Vaiphasa, C. (2006). Consideration of smoothing techniques for hyperspectral remote sensing.

906 Journal of Photogrammetry and Remote Sensing, 60, 91-99.

907 Van Heukelem, L., \& Thomas, C. S. (2001). Computer-assisted high-performance liquid

908 chromatography method development with applications to the isolation and analysis of

909 phytoplankton pigments. Journal of Chromatography A, 910, 31-49.

910 Vidussi, F., Claustre, H., Manca, B. B., Luchetta, A., \& Marty, J.-C. (2001). Phytoplankton

911 pigment distribution in relation to upper thermocline circulation in the eastern Mediterranean

912 Sea during winter. Journal of Geophysical Research, 106, 19939-19956. 
913 Wright, S. W., Thomas, D. P., Marchant, H. J., Higgins, H. W., Mackey, M. D., \& Mackey, D. J.

914 (1996). Analysis of phytoplankton of the Australian sector of the Southern Ocean:

915 comparisons of microscopy and size-frequency data with interpretations of pigment HPLC

916 data using the CHEMTAX matrix factorisation program. Marine Ecology Progress Series, $917 \quad 144,285.98$.

918 Zapata, M., Rodriguez, F., \& Garrido, J. L. (2000). Separation of chlorophylls and carotenoids 919 from marine phytoplankton: A new HPLC method using a reversed-phase C8 column and 920 pyridine-containing mobile phases. Marine. Ecology Progress Series, 195, 29-45. 
922 Table 1. Summary of phytoplankton pigment data for the nine stations selected in this study.

923 The stations are sorted into different classes characterized by differing pigment assemblages

924 based upon the ratios of the concentrations of two dominant accessory pigments to total

925 chlorophyll- $a$, TChla (see the 2 nd and 3rd columns from the left). The ratios of the

926 concentrations of six dominant pigments to TChla are also displayed, with the two most

927 dominant accessory pigments indicated within the shaded areas. Pigment abbreviations are:

928 MVChl $a$ = monovinyl chlorophyll- $a$, DVChl $a$ = divinyl chlorophyll- $a$, Fuco = fucoxanthin, Hex

$929=19$ ' hexanoyloxyfucoxanthin, But = 19' butanoloxyfucoxanthin, MVChl $b=$ monovinyl

930 chlorophyll- $b$, Chl $c 2=$ chlorophyll- $c 2$, Zea = zeaxanthin, Pra = prasinoxanthin, Dia $=$

931 diadinoxanthin, and $\alpha$-caro $=\alpha$-carotene.

932

\begin{tabular}{|c|c|c|c|c|c|c|c|c|c|}
\hline $\begin{array}{l}\text { Station } \\
\text { ID }\end{array}$ & $\begin{array}{c}2 \text { dominant } \\
\text { pigments }\end{array}$ & Class & $\begin{array}{c}\text { TChla } \\
{\left[\mathrm{mg} / \mathrm{m}^{3}\right]}\end{array}$ & & of conce & rations of & minant $\mathrm{p}$ & ments to & $\mathrm{hl} a$ \\
\hline \multirow{2}{*}{1} & \multirow{2}{*}{ Fuco $\approx$ MVChl $b$} & \multirow{2}{*}{ A } & \multirow{2}{*}{0.62} & MVChla & Fuco & MVChl $b$ & Chlc2 & Pra & Hex \\
\hline & & & & 0.95 & 0.22 & 0.21 & 0.11 & 0.07 & 0.07 \\
\hline \multirow{2}{*}{6} & \multirow{2}{*}{ DVChl $a>$ Zea } & \multirow{2}{*}{ B } & \multirow{2}{*}{0.28} & DVChl $a$ & MVChla & Zea & Hex & $\alpha$-caro & Chlc2 \\
\hline & & & & 0.50 & 0.47 & 0.31 & 0.18 & 0.09 & 0.09 \\
\hline \multirow{2}{*}{12} & \multirow{2}{*}{ DVChl $a \approx$ Zea } & \multirow{2}{*}{$\mathrm{C} 1$} & \multirow{2}{*}{0.14} & MVChla & DVChl $a$ & Zea & Hex & Chlc2 & But \\
\hline & & & & 0.54 & 0.44 & 0.40 & 0.24 & 0.09 & 0.09 \\
\hline \multirow{2}{*}{37} & \multirow{2}{*}{ DVChl $a \approx$ Zea } & \multirow{2}{*}{$\mathrm{C} 2$} & \multirow{2}{*}{0.15} & Zea & DVChl $a$ & MVChl $a$ & Hex & Dia & $a$-caro \\
\hline & & & & 0.63 & 0.58 & 0.40 & 0.17 & 0.10 & 0.10 \\
\hline \multirow{2}{*}{44} & \multirow{2}{*}{ DVChl $a \approx$ Zea } & \multirow{2}{*}{$\mathrm{C} 3$} & \multirow{2}{*}{0.22} & DVChla & Zea & MVChl $a$ & Hex & $\alpha$-caro & Chlc2 \\
\hline & & & & 0.56 & 0.50 & 0.42 & 0.17 & 0.08 & 0.08 \\
\hline \multirow{2}{*}{46} & \multirow{2}{*}{ DVChl $a \approx$ Zea } & \multirow{2}{*}{$\mathrm{C} 4$} & \multirow{2}{*}{0.14} & Zea & DVChla & MVChla & Hex & Dia & MVChl $b$ \\
\hline & & & & 0.52 & 0.50 & 0.49 & 0.20 & 0.09 & 0.08 \\
\hline \multirow{2}{*}{48} & \multirow{2}{*}{ Hex $>$ Zea } & \multirow{2}{*}{$\mathrm{D}$} & \multirow{2}{*}{0.21} & MVChla & Hex & Zea & DVChla & But & Dia \\
\hline & & & & 0.76 & 0.48 & 0.25 & 0.21 & 0.18 & 0.16 \\
\hline \multirow{2}{*}{51} & \multirow{2}{*}{ Hex $>$ Fuco } & \multirow{2}{*}{$\mathrm{E}$} & \multirow{2}{*}{0.26} & MVChla & Hex & Fuco & Dia & Chlc2 & But \\
\hline & & & & 0.86 & 0.35 & 0.24 & 0.23 & 0.18 & 0.13 \\
\hline \multirow{2}{*}{59} & \multirow{2}{*}{$\mathrm{Zea} \approx \mathrm{Hex}$} & \multirow{2}{*}{$\mathrm{F}$} & 0 & MVChla & Zea & Hex & Dia & DVChla & But \\
\hline & & & 0.11 & 0.80 & 0.39 & 0.34 & 0.21 & 0.18 & 0.12 \\
\hline
\end{tabular}

933

934

935 
936 Table 2. A comparison of similarity indices between pigment-based clusters and reflectance-

937 based clusters for the different sources of reflectance data that are depicted in Fig. 12. For the

938 case of the second derivative of hyperspectral reflectance, the result of computations for two

939 different spectral regions is given.

\begin{tabular}{lcc}
\hline \multicolumn{1}{c}{ Reflectance data } & $\begin{array}{c}\text { Rand } \\
\text { index }\end{array}$ & Cophenetic index \\
\hline 3 band ratios based on 4 SeaWiFS bands & 0.69 & 0.39 \\
\hline Multispectral (13 bands) & 0.69 & 0.39 \\
\hline Hyperspectral (325 bands, range 300-725 nm) & 0.69 & 0.39 \\
\hline Hyperspectral 2nd derivative (300-725 nm) & 0.78 & 0.53 \\
\hline Hyperspectral 2nd derivative $(435-495 \mathrm{~nm})$ & 1 & 0.65 \\
\hline
\end{tabular}

940

941 


\section{Figure captions}

943 Figure 1. Map depicting the location of full stations sampled along the north-to-south ANT-

944 XXIII/1 cruise track in the eastern Atlantic during October and November, 2005. Each full

945 station consisted of in situ optical measurements accompanied by discrete water sample analyses.

946 Stations chosen for use in the cluster analysis are identified by filled circles and labeled with the

947 station ID.

948

949 Figure 2. Hyperspectral $(1 \mathrm{~nm})$ determinations of the remote-sensing reflectance $R_{r s}(\lambda)$ obtained

950 from radiative transfer simulations (solid line) compared with in situ multispectral measurements

951 at 13 discrete bands (solid circles). Each panel illustrates a different station location.

952

953 Figure 3. A schematic diagram illustrating the general approach to hierarchical cluster analysis

954 and similarity determination. The dendrogram obtained with pigment composition as the input

955 (upper pathway) is used as the reference for comparison with results obtained utilizing various

956 optical data as input.

957

958 Figure 4. (a) Dendrogram obtained for the nine stations using 24 pigment to total chlorophyll- $a$

959 (TChl $a$ ) ratios determined from the CHORS HPLC analysis. (b) Linkage distances obtained

960 from the cluster analysis shown in (a) as a function of distance along the dendrogram. (c)

961 Similar to (a), but using input ratios calculated from 8 diagnostic pigments (see text for details).

962

963 Figure 5. Chlorophyll-specific normalized absorption coefficients for the nine stations 
964 corresponding to: (a) absorption of phytoplankton, $a_{n, p h} *(\lambda)$, (b) absorption of pure seawater plus 965 phytoplankton, $a_{n, w+p h} *(\lambda)$, and (c) total absorption, $a_{n}^{*}(\lambda)$.

966

967 Figure 6. Results of cluster analysis applied to absorption data from the nine stations. The left

968 panels represent dendrograms obtained using the different absorption components of (a) $a_{n} *(\lambda)$,

969 (c) $a_{n, w+p h} *(\lambda)$, and (e) $a_{n, p h} *(\lambda)$, and the right panels $(\mathrm{b}, \mathrm{d}, \mathrm{f})$ illustrate results obtained using

970 each respective component's second derivative spectrum.

971

972 Figure 7. Similarity indices between absorption-based and pigment-based cluster trees obtained

973 for the nine stations using different combinations of spectral range for (a) $a_{n} *(\lambda)$, (b) $a_{n, w+p h} *(\lambda)$

974 and (c) $a_{n, p h} *(\lambda)$. The y-axis indicates the lower limit of the spectral range $\left(\lambda_{\min }\right)$ and the x-axis

975 the upper limit of the spectral range $\left(\lambda_{\max }\right)$ utilized in the cluster analysis. Left and right panels

976 depict the cophenetic and Rand indices, respectively.

977

978 Figure 8. Similar to Fig. 7, but based on cluster trees obtained using different spectral range

979 combinations for the second derivative spectra of (a) $a_{n} *(\lambda)$, (b) $a_{n, w+p h} *(\lambda)$ and (c) $a_{n, p h} *(\lambda)$.

980 Optimal values for band separation and window size determined from prior analyses $(B S=W S=$

$9819 \mathrm{~nm}$, see text for details) were used in the calculation of derivative spectra.

982

983 Figure 9. Histograms of cophenetic indices obtained for all combinations of spectral ranges

984 shown in Fig. 8 based on (a) the absorption of phytoplankton, $a_{n, p h} *(\lambda)$, and (b) its second

985 derivative spectra. 
987 Figure 10. Cophenetic indices obtained from the cluster and similarity analysis of the second 988 derivative spectra of $a_{n, p h}{ }^{*}$, in which different parameter sets for the derivative analysis are 989 considered. The analysis was conducted using the optimal spectral region from 420 to $515 \mathrm{~nm}$.

990 The $y$-axis indicates the size of the filter window used in smoothing of the absorption spectra

991 (WS), and the $\mathrm{x}$-axis represents the band separation used in the calculation of the derivative 992 calculation $(B S)$.

993

994 Figure 11. Hydrolight-simulated $R_{r s}(\lambda)$ spectra, normalized at $555 \mathrm{~nm}$, computed for the nine 995 stations using measured IOPs as input.

997 Figure 12. Dendrograms resulting from cluster analysis of the nine stations calculated using four 998 different sets of input data vectors: (a) three reflectance band ratios of $R_{r s}(\lambda)$ based on 4 SeaWiFS 999 wavebands obtained from measurements with SPMR instrument, (b) 13 band ratios 1000 corresponding to multispectral measurements of $R_{r s}(\lambda)$ with SPMR instrument, (c) hyperspectral $1001(1 \mathrm{~nm})$ ordinary (non-differentiated) normalized $R_{r s}(\lambda)$ spectra computed from the Hydrolight 1002 simulations, and (d) second derivative of hyperspectral normalized $R_{r s}(\lambda)$ spectra obtained using 1003 optimal values for band separation and smoothing filter window (i.e., $B S=W S=27 \mathrm{~nm}$ ).

1005 Figure 13. Linkage distances as a function of distance along the dendrogram for each cluster tree 1006 depicted in Fig.12. 
1008 Figure 14. Similarity indices between reflectance-based and pigment-based cluster trees

1009 obtained for the nine stations using different combinations of spectral ranges for the second

1010 derivative of the hyperspectral normalized $R_{r s}(\lambda)$. Optimal values of $B S=W S=27 \mathrm{~nm}$,

1011 determined from prior analyses, were used for the calculation of derivative spectra. The y-axis

1012 indicates the lower limit of the spectral range $\left(\lambda_{\min }\right)$ and the $\mathrm{x}$-axis the upper limit of the spectral

1013 range $\left(\lambda_{\max }\right)$ utilized in the cluster analysis. Panels (a) and (b) depict the cophenetic and Rand

1014 indices, respectively.

1015

1016 Figure 15. (a) Cophenetic and (b) Rand indices obtained from the comparison of pigment-based

1017 cluster trees with trees computed from the second derivative of hyperspectral normalized $R_{r s}(\lambda)$,

1018 in which different choices for parameters of the derivative analysis are considered. The analysis

1019 has been carried out for the optimal spectral region from 435 and $495 \mathrm{~nm}$. The y-axis indicates

1020 the size of the filter window used in the smoothing of spectra (WS), and the $\mathrm{x}$-axis the band

1021 separation used in the derivative calculation $(B S)$.

1022

1023 Figure 16. The second derivative spectra at each station of the (a) chlorophyll-specific

1024 normalized phytoplankton absorption coefficient, $a_{n, p h} *(\lambda)$, and (b) normalized hyperspectral

1025 remote-sensing reflectance, $R_{r s}(\lambda) / R_{r s}(555)$. The derivative spectra are depicted for the optimal

1026 spectral ranges of $370-716 \mathrm{~nm}$ for absorption, and $435-510 \mathrm{~nm}$ for reflectance. Optimal values

1027 for band separation and smoothing filter window were used for the derivative calculations, i.e.,

$1028 B S=W S=9 \mathrm{~nm}$ for the absorption data and $B S=W S=27 \mathrm{~nm}$ for the reflectance data. 
Figure 1

Click here to download high resolution image

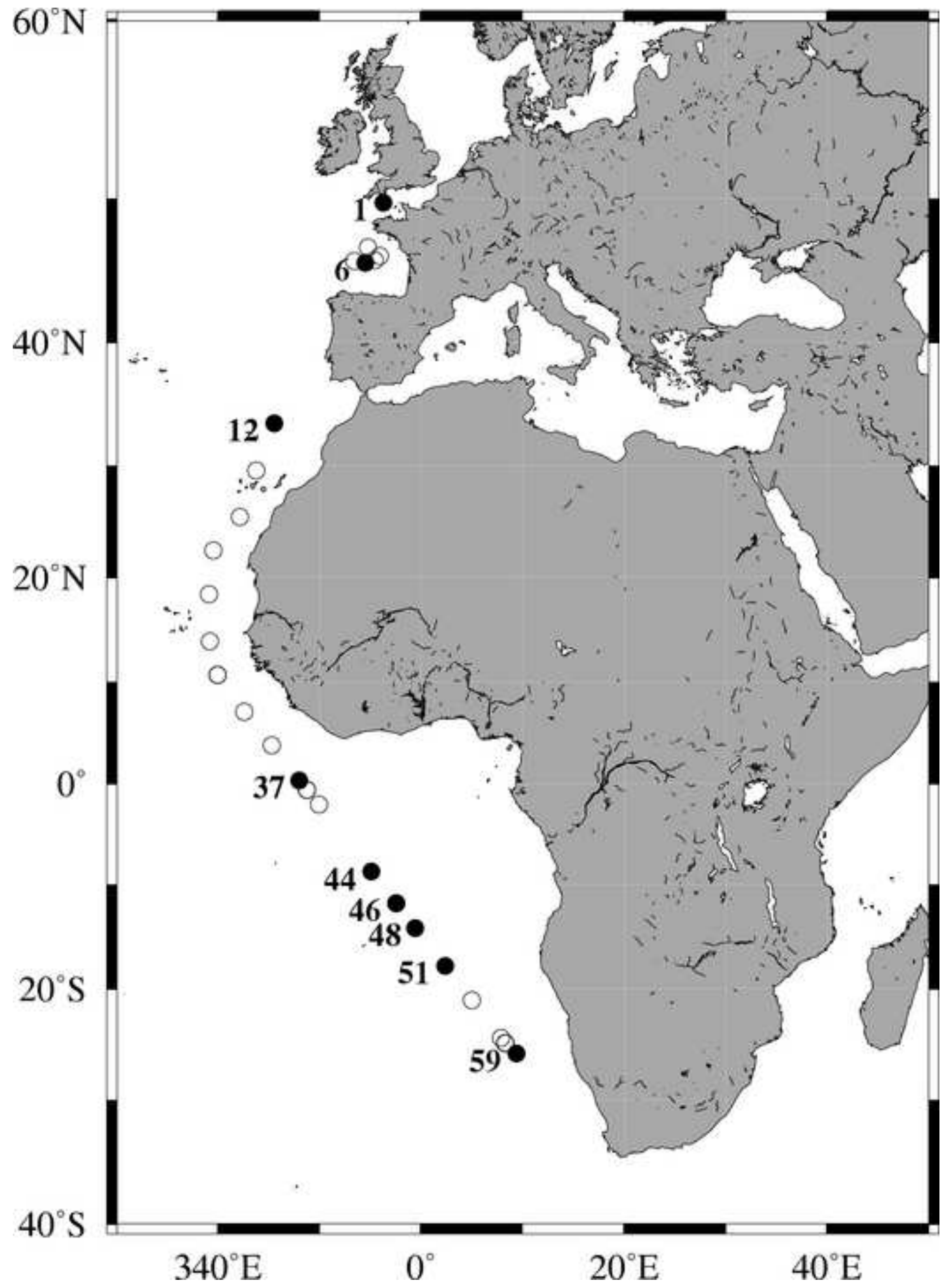



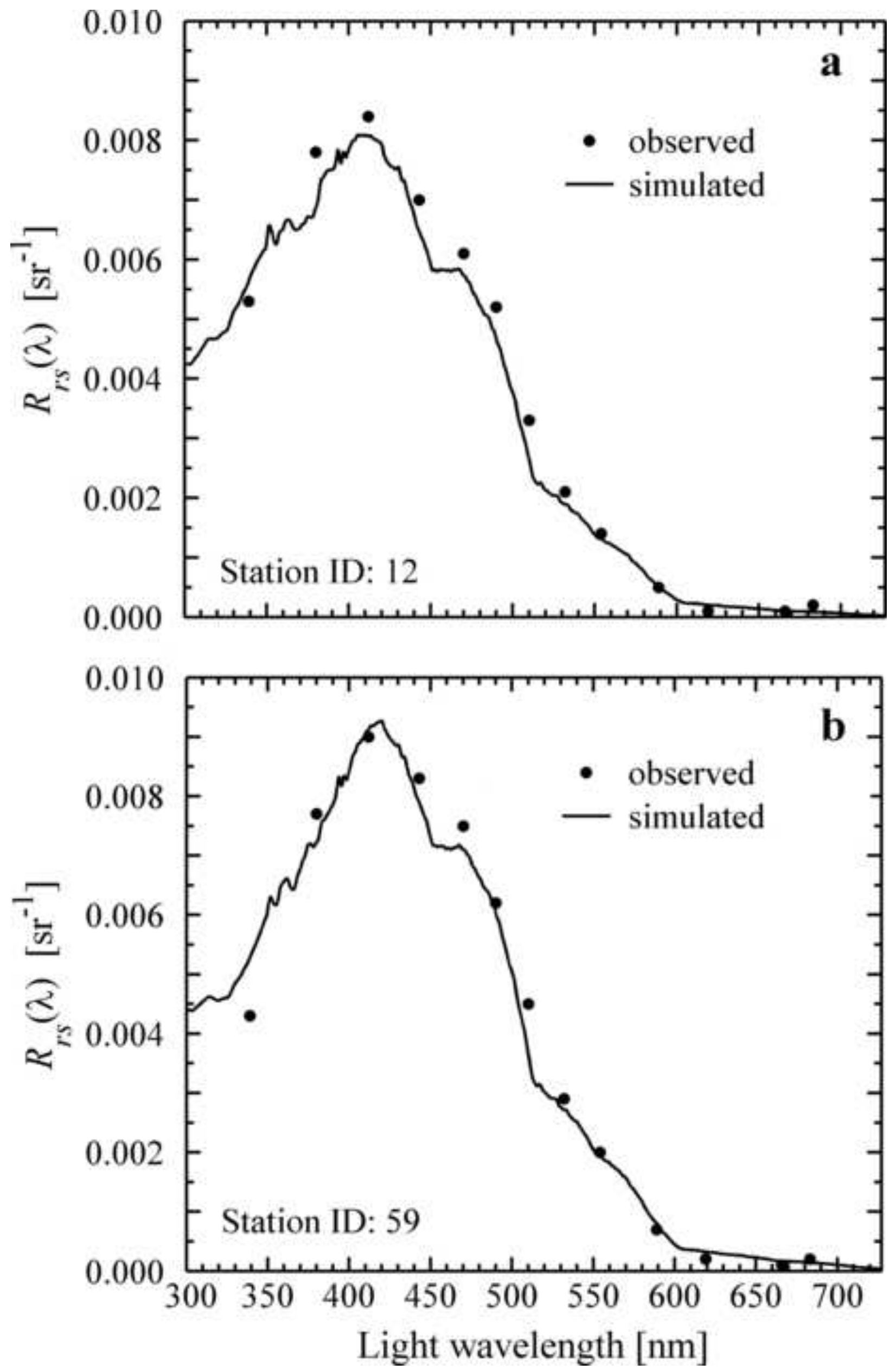


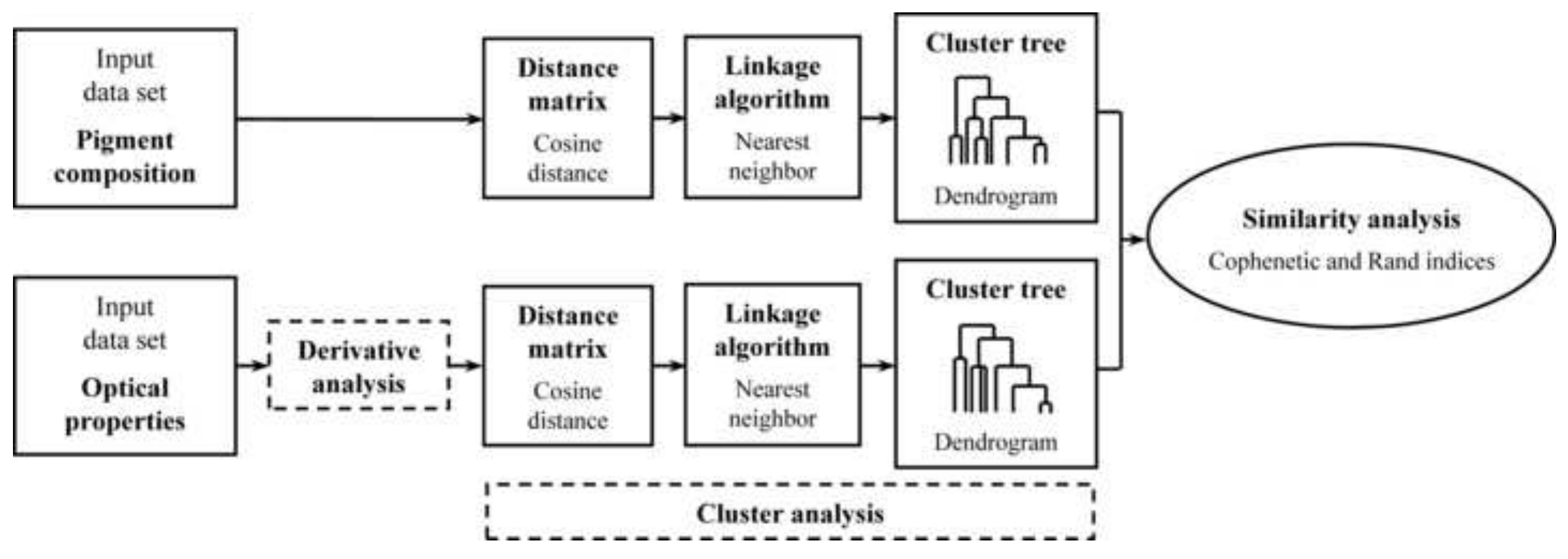




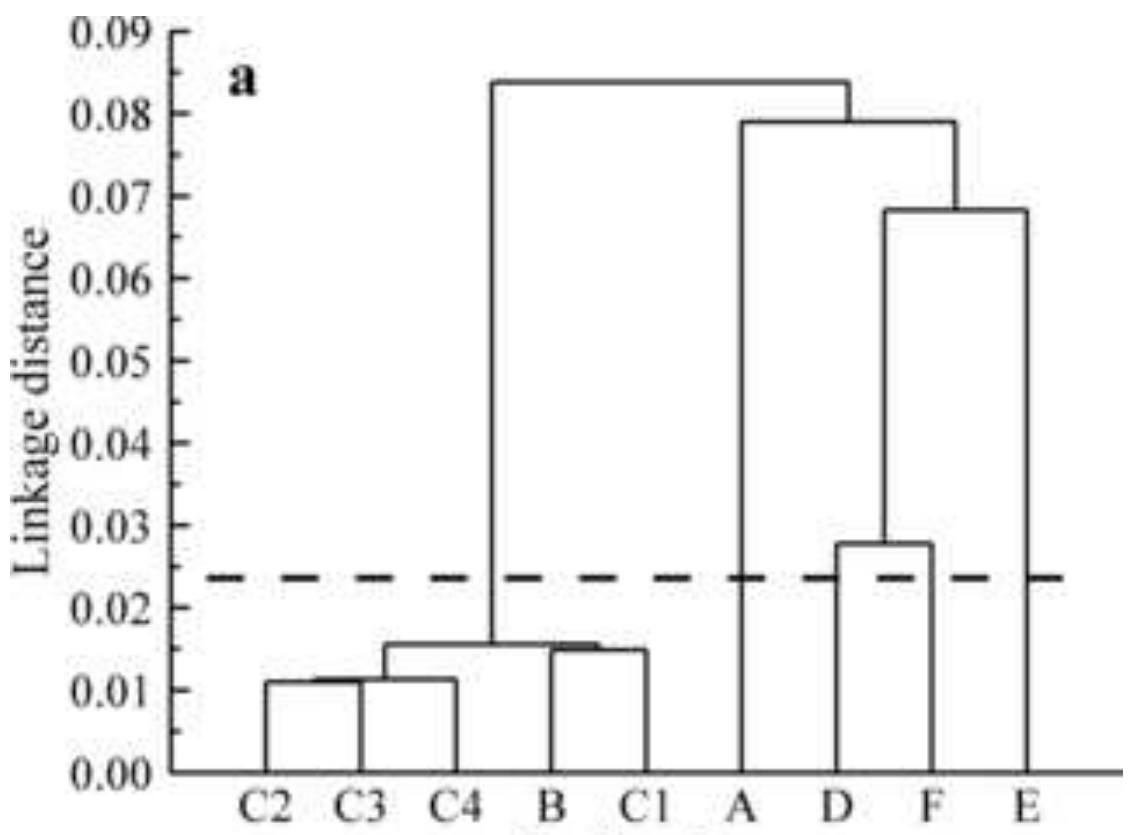

Station class

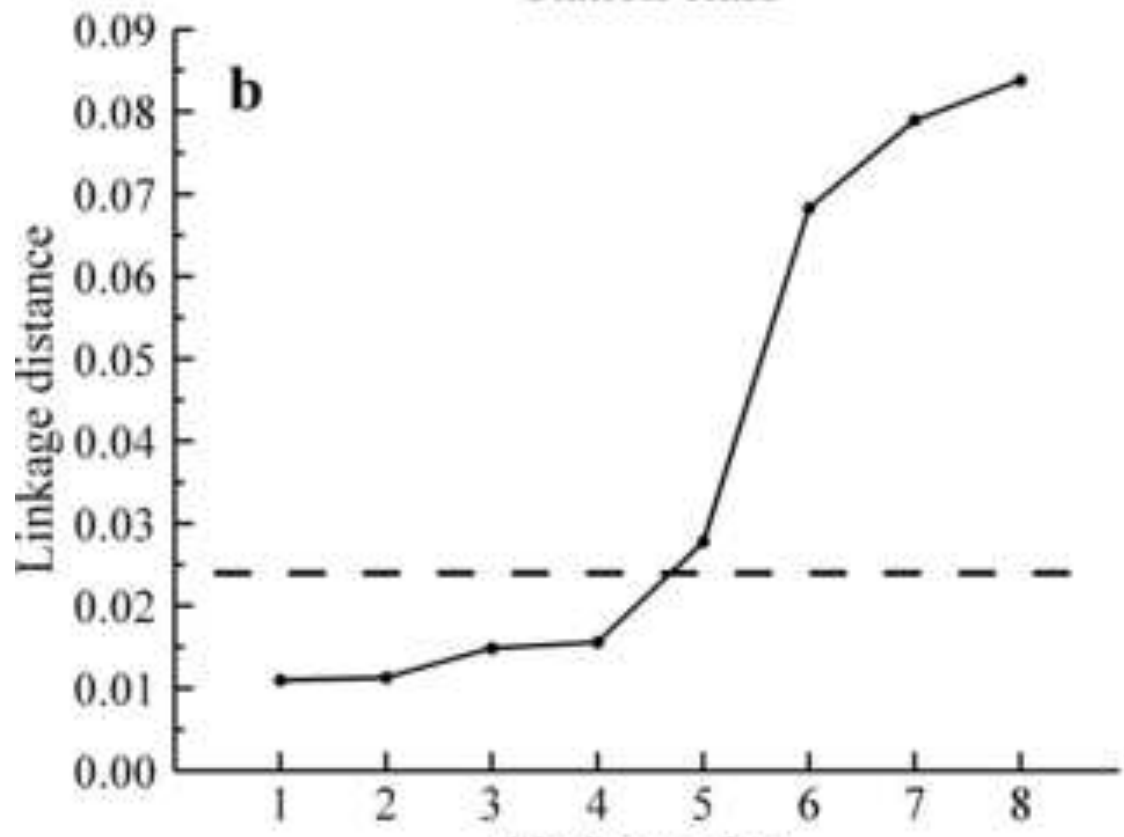

Node number

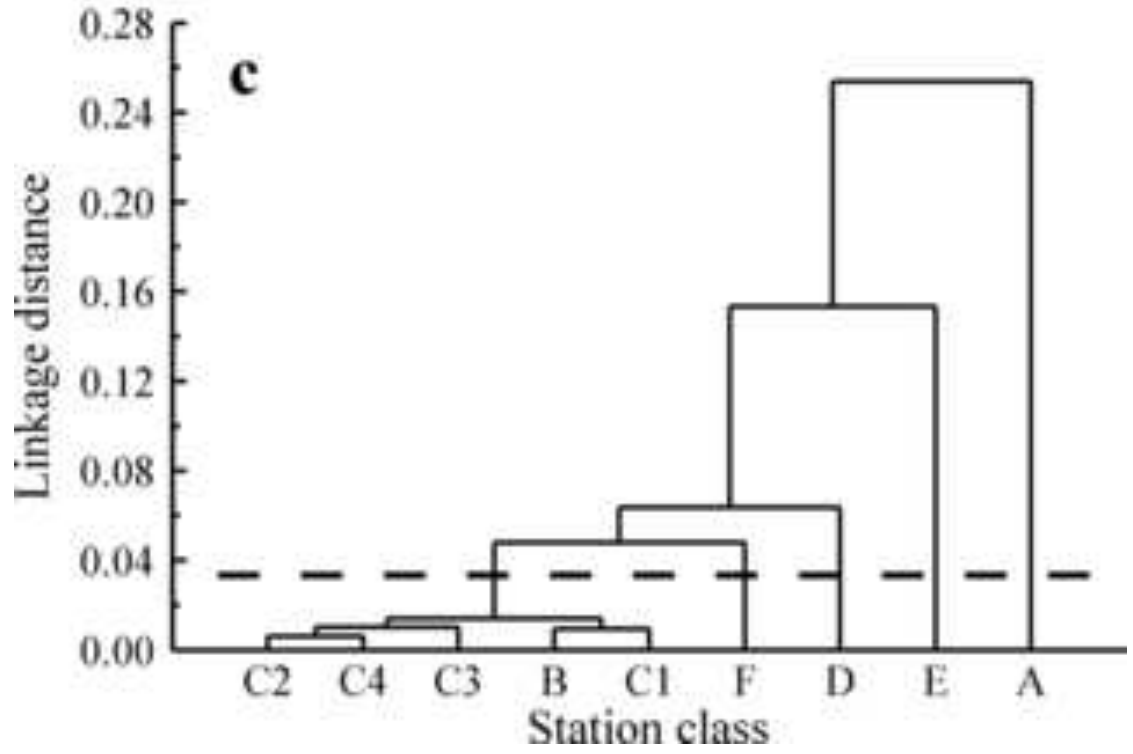



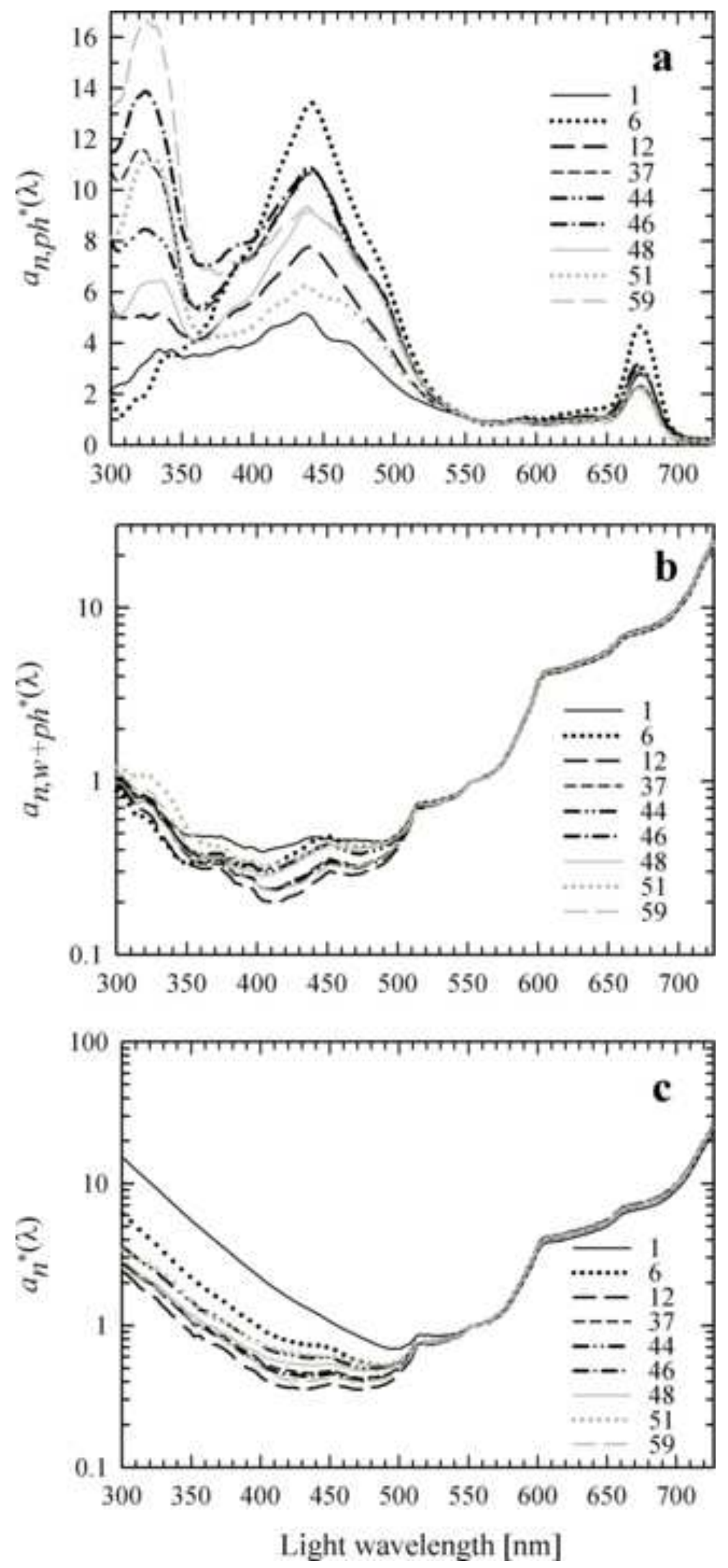
Ordinary spectra
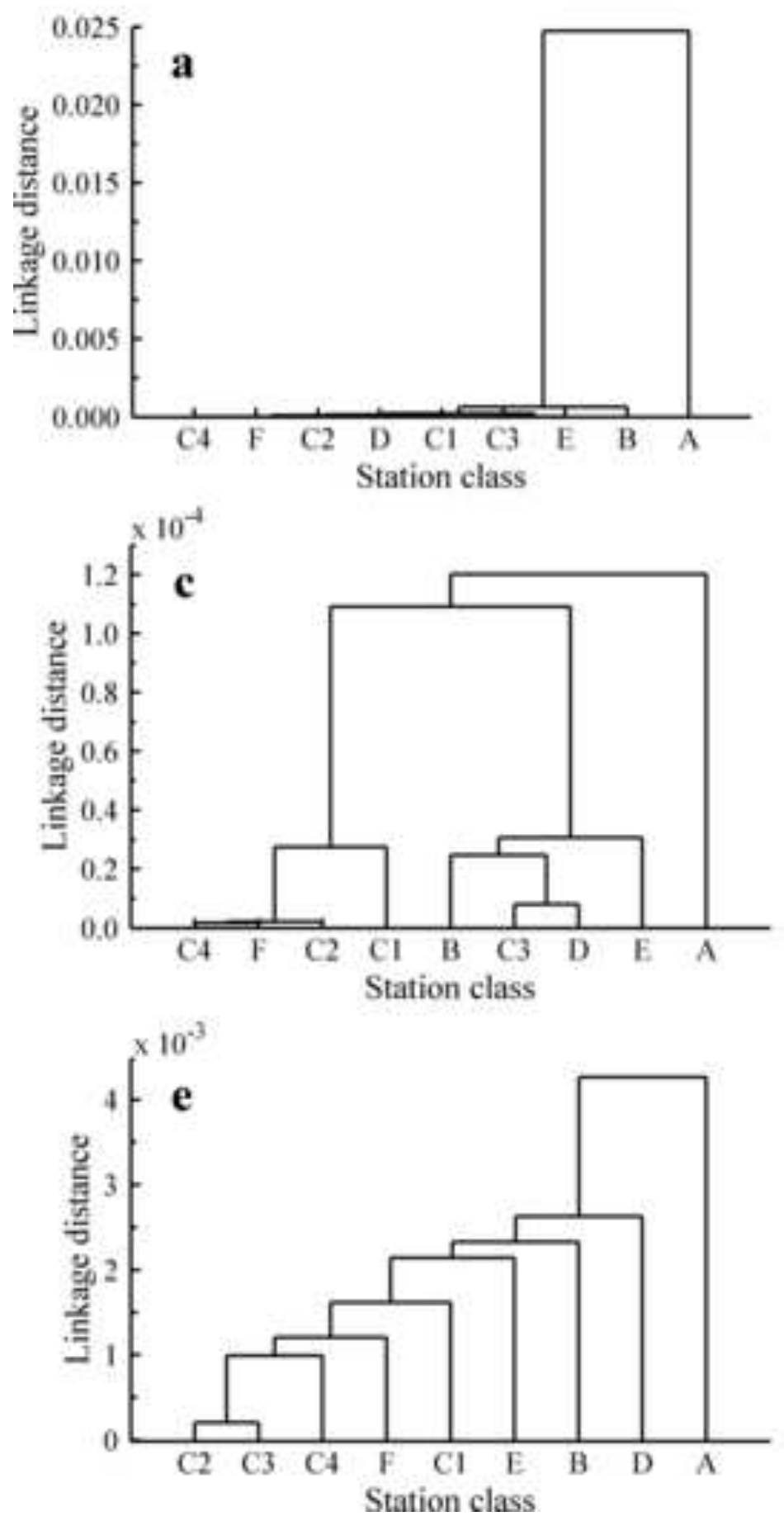

Derivative spectra
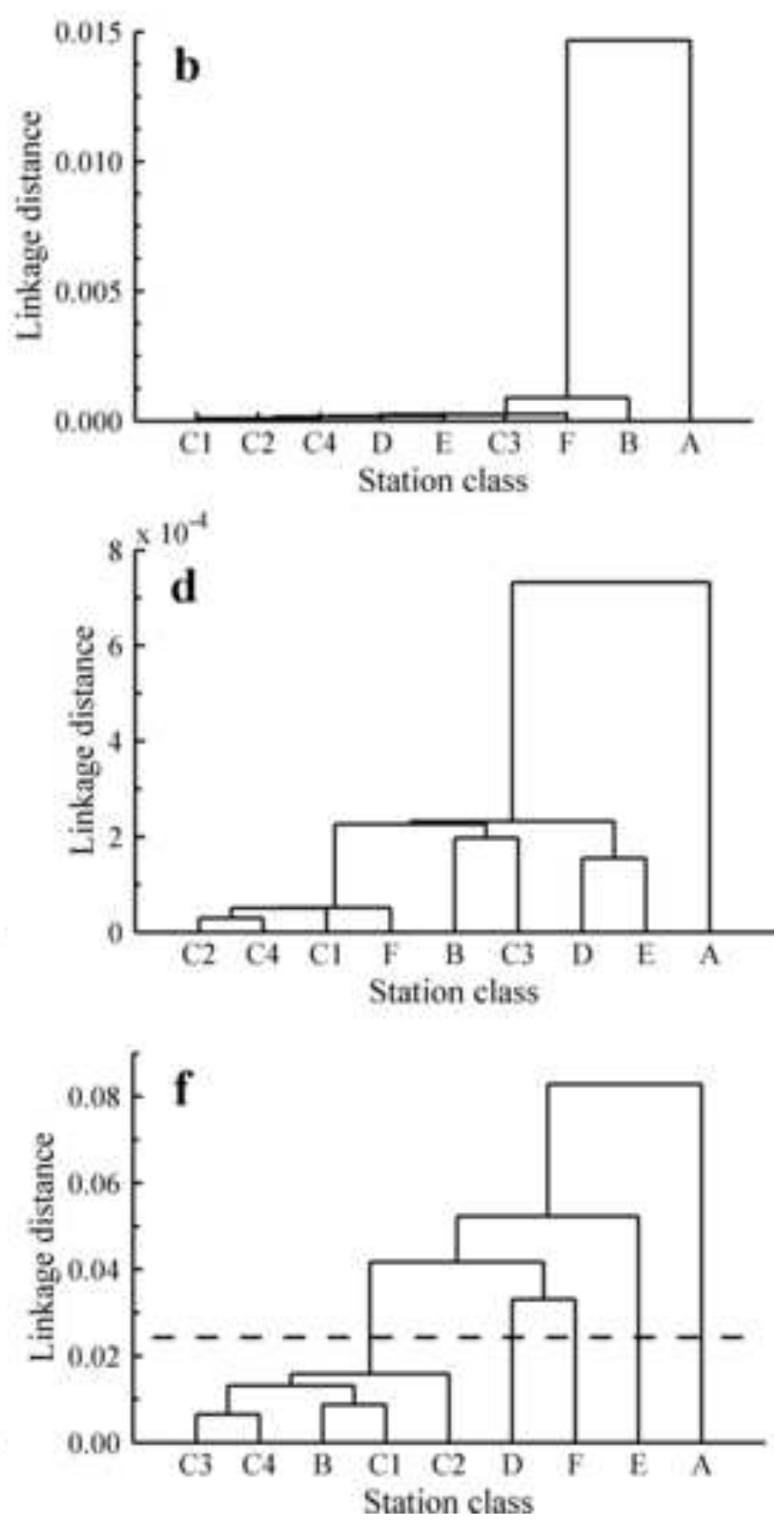
Cophenetic index
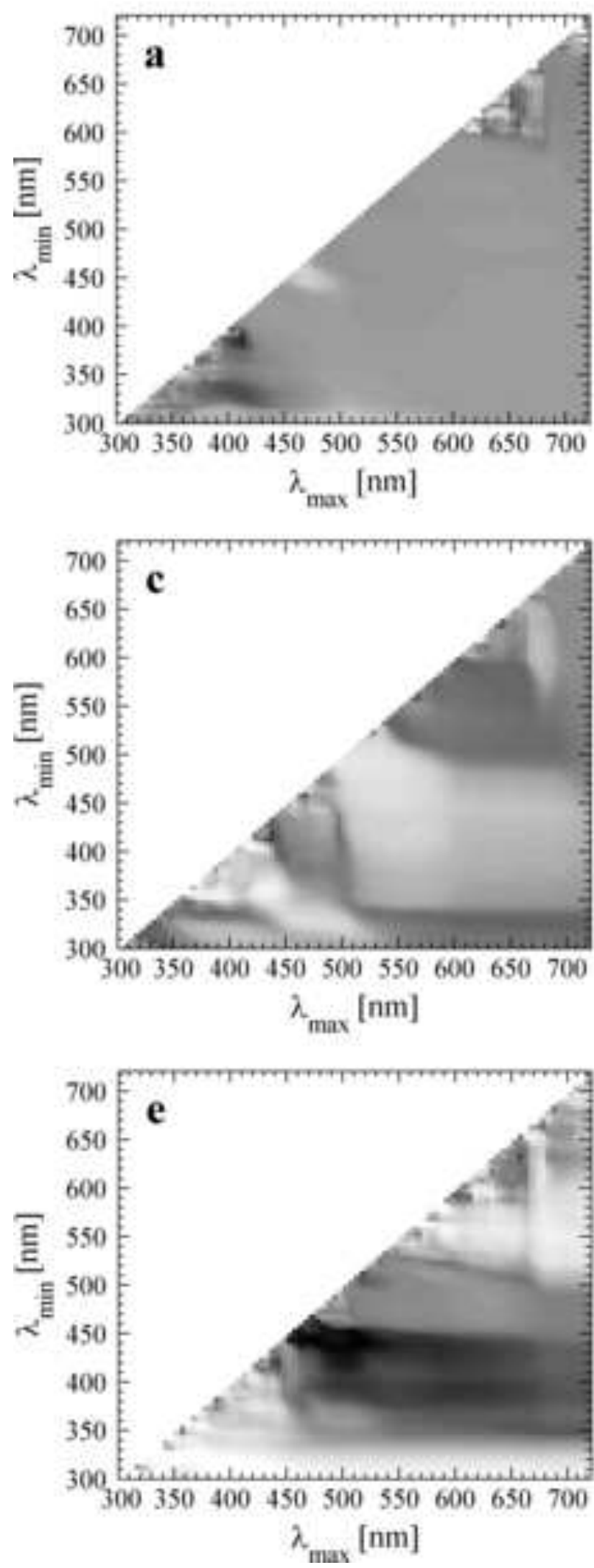

Rand index
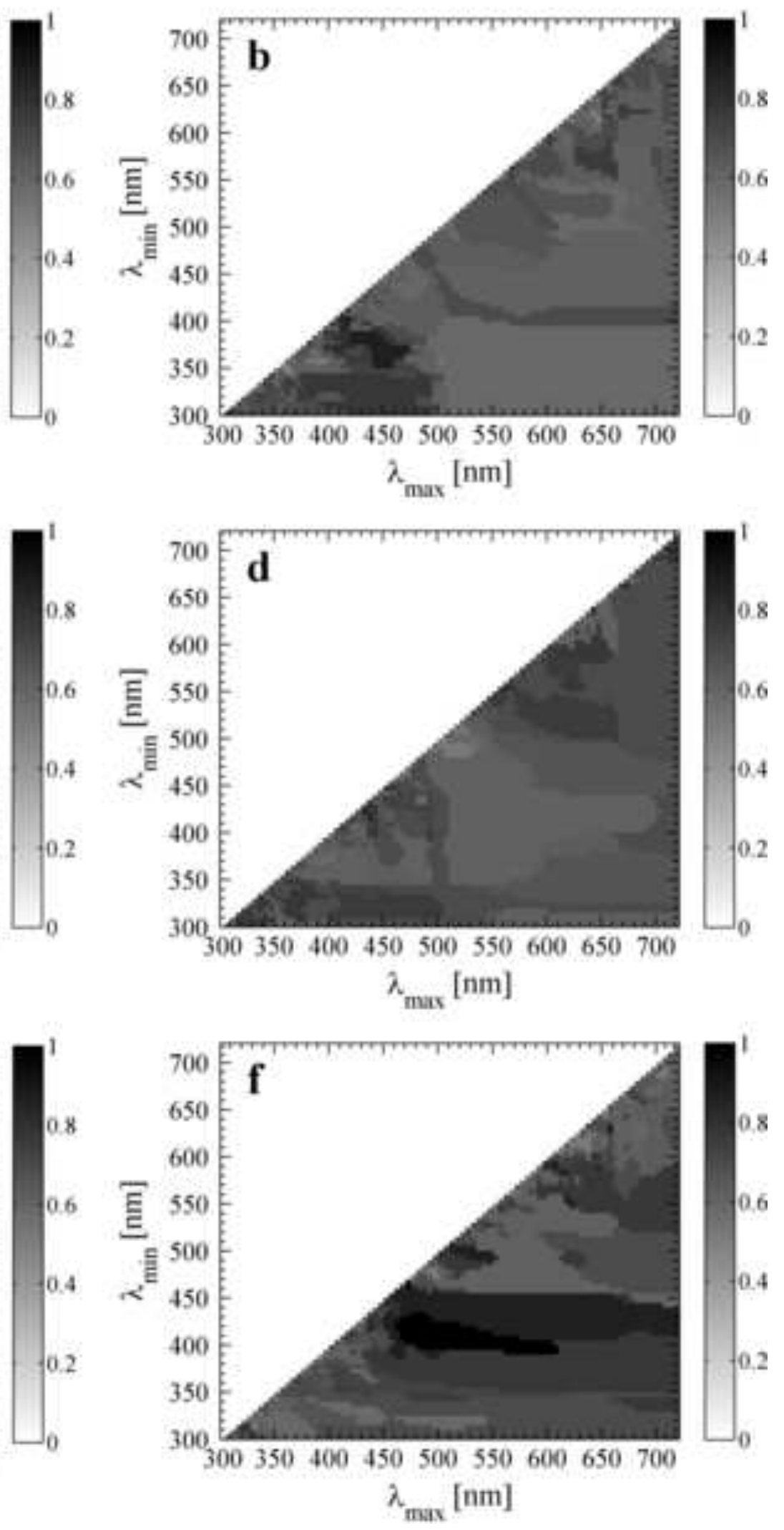


\section{Cophenetic index}
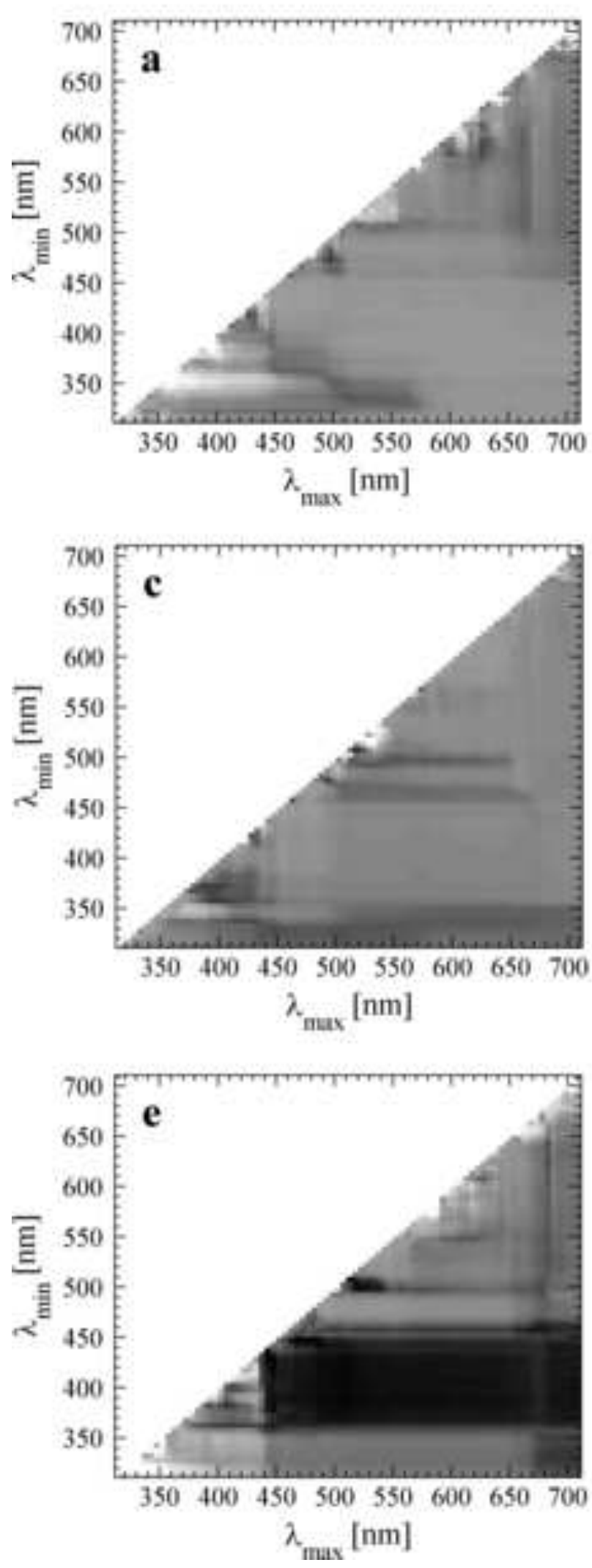

Rand index
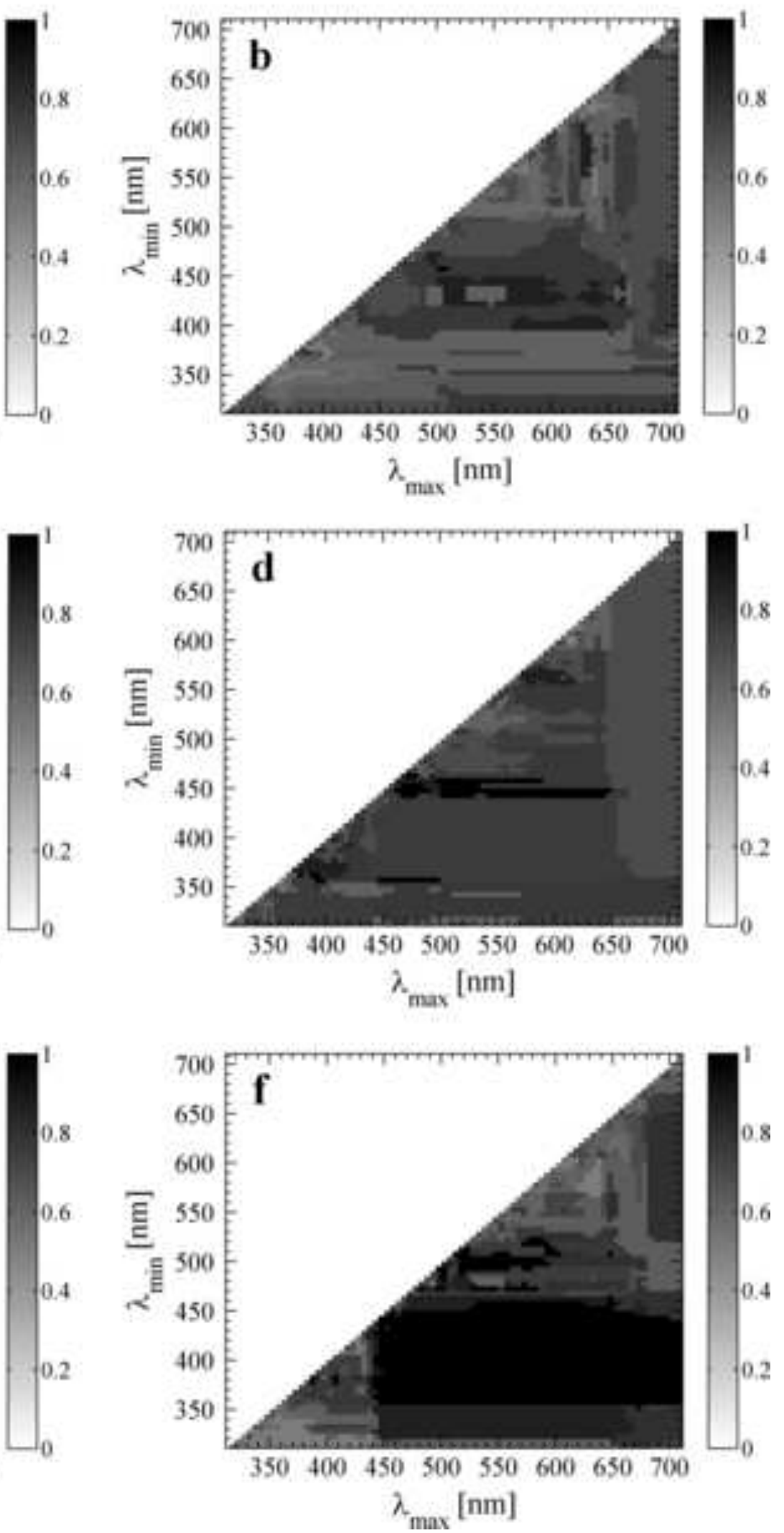

0.8

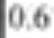

0.4

0.2

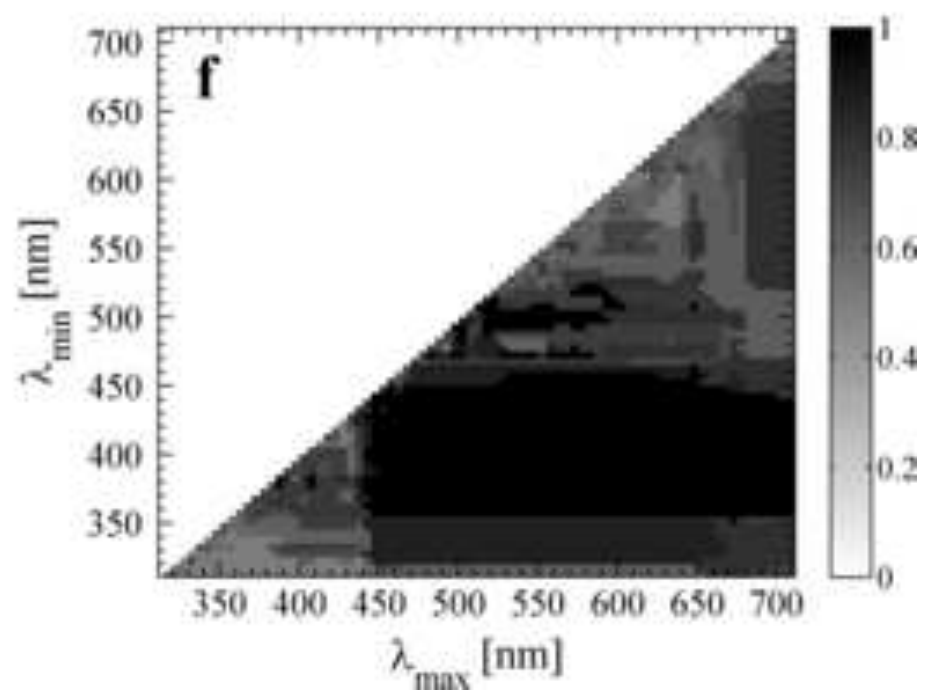


Click here to download high resolution image
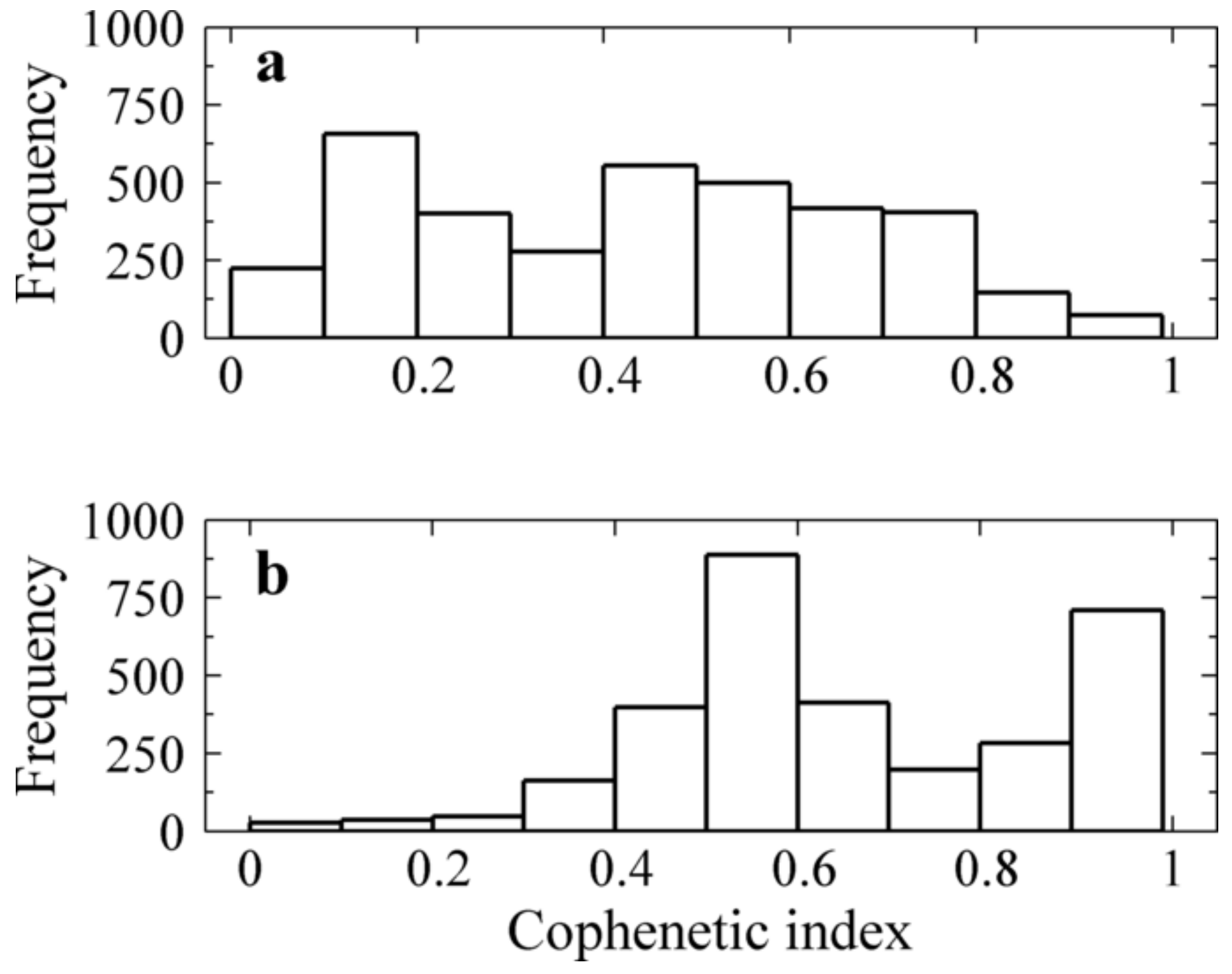
Figure 10
Click here to download high resolution image

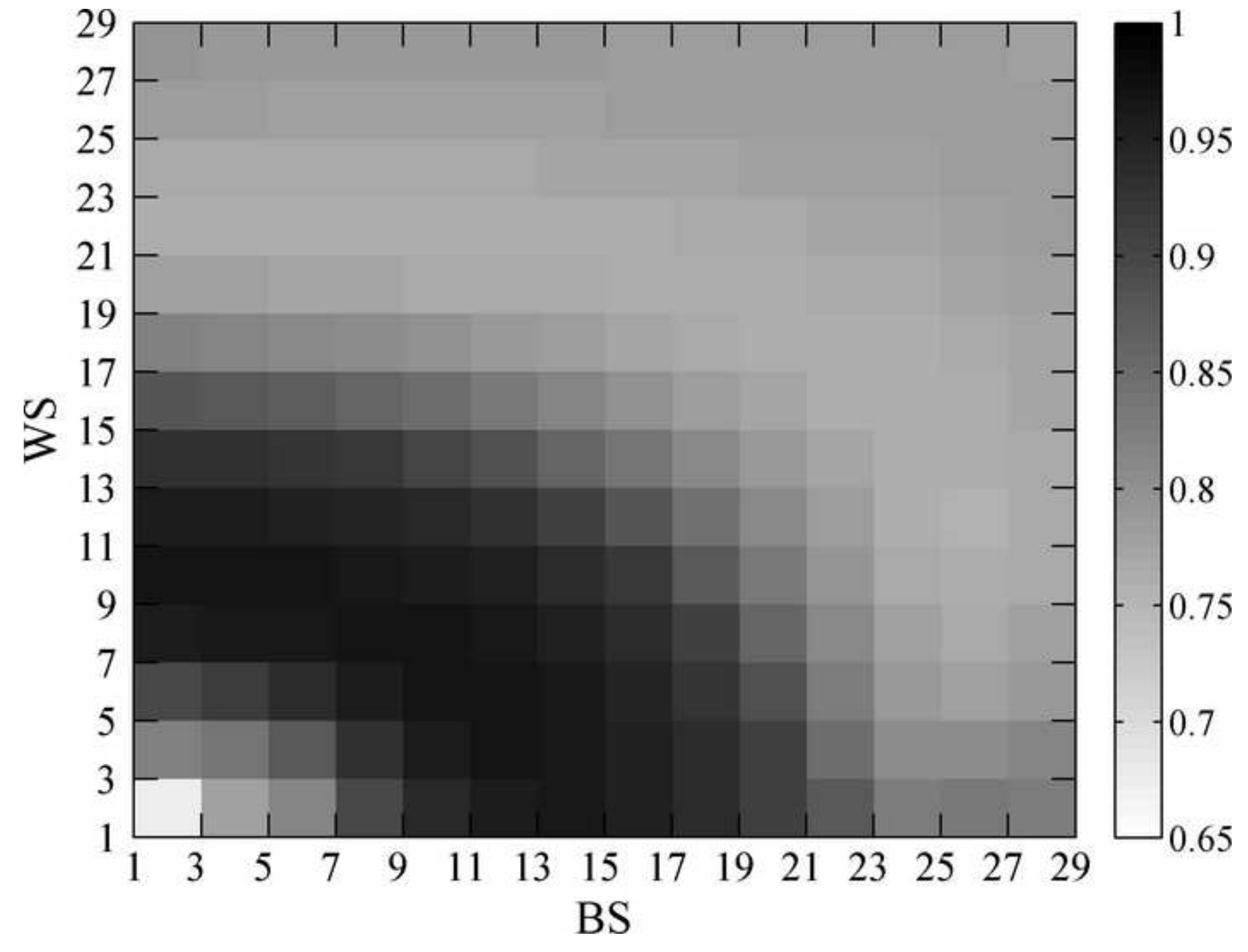




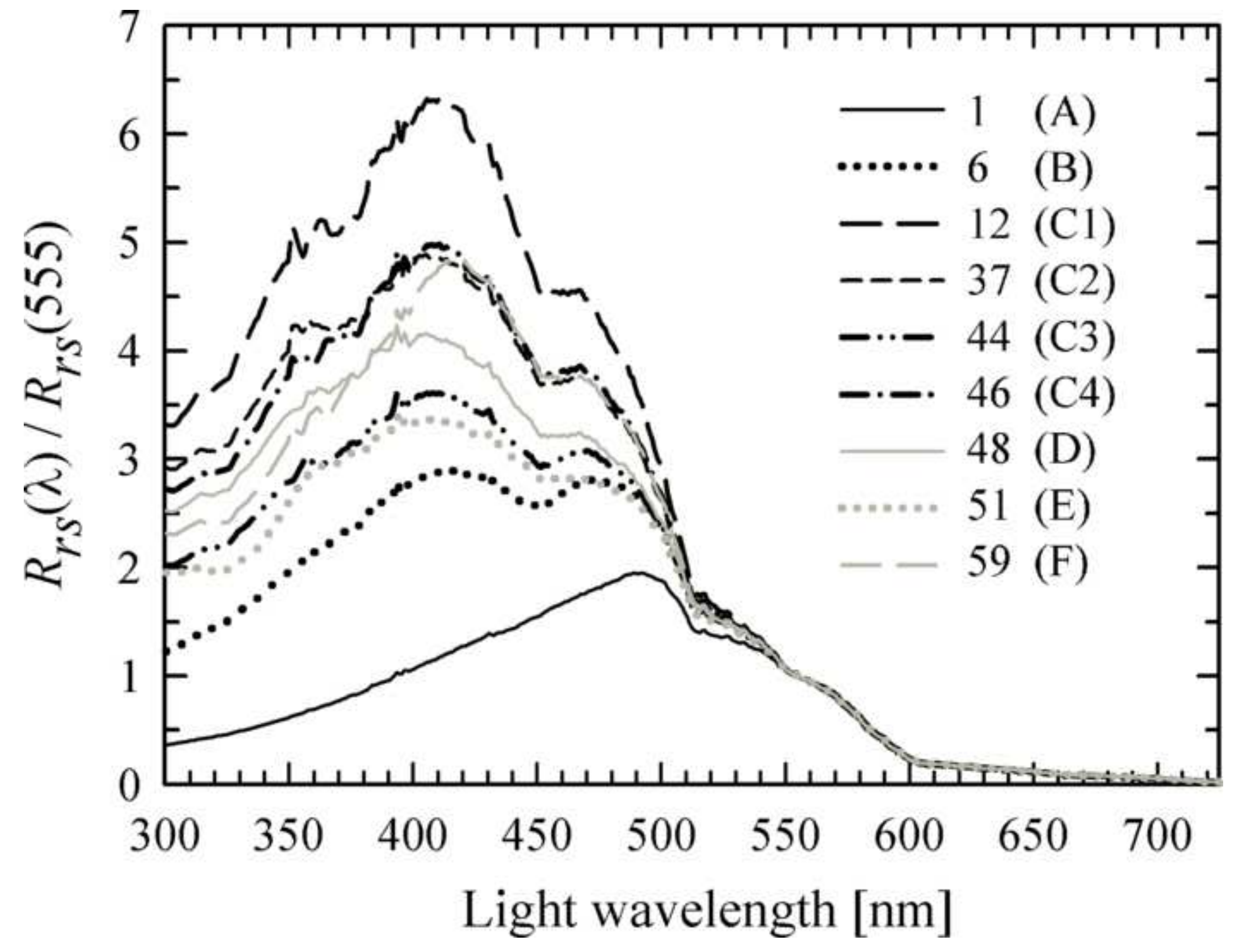

Figure 11
lick here to download high resolution image 

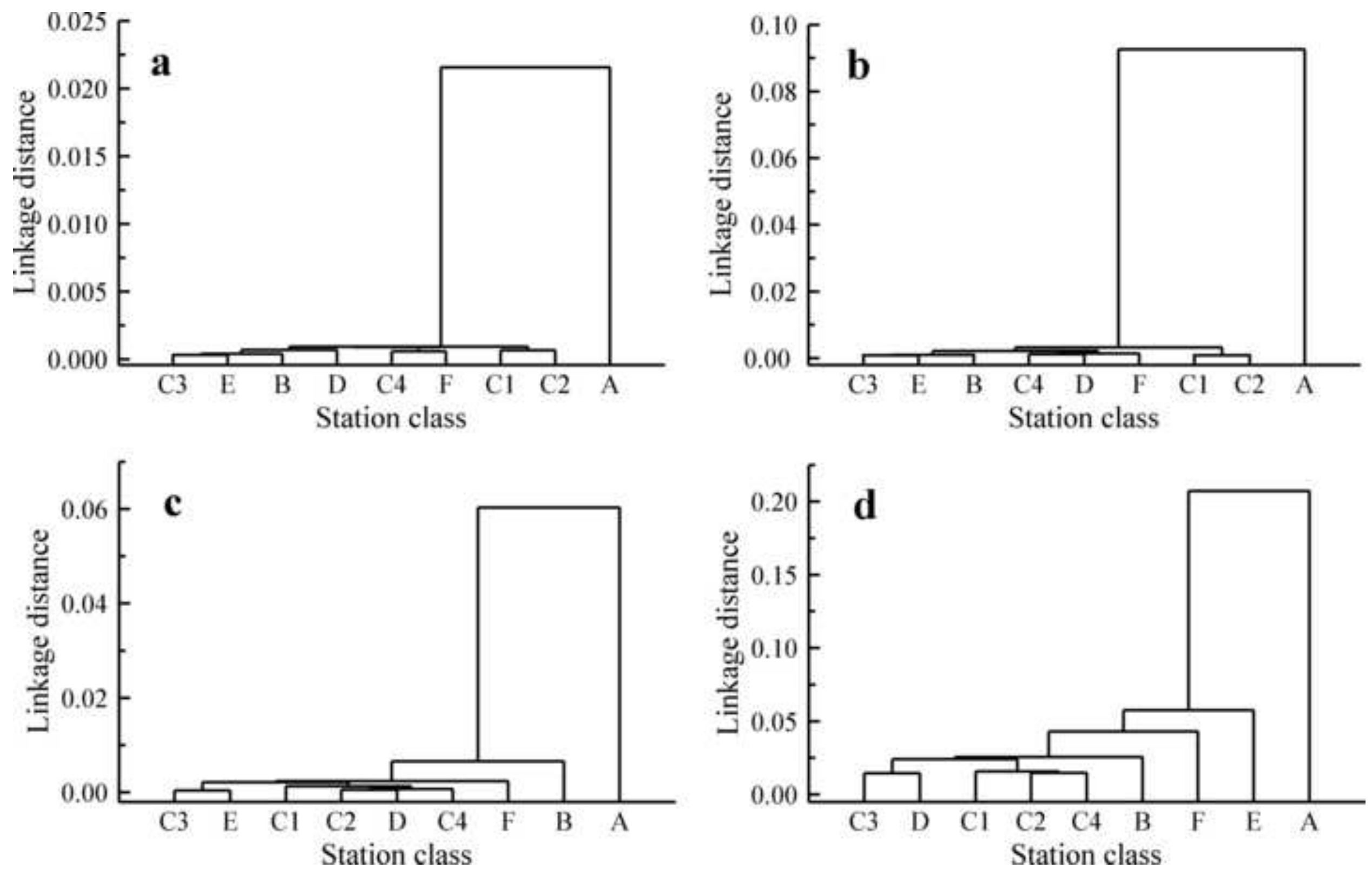


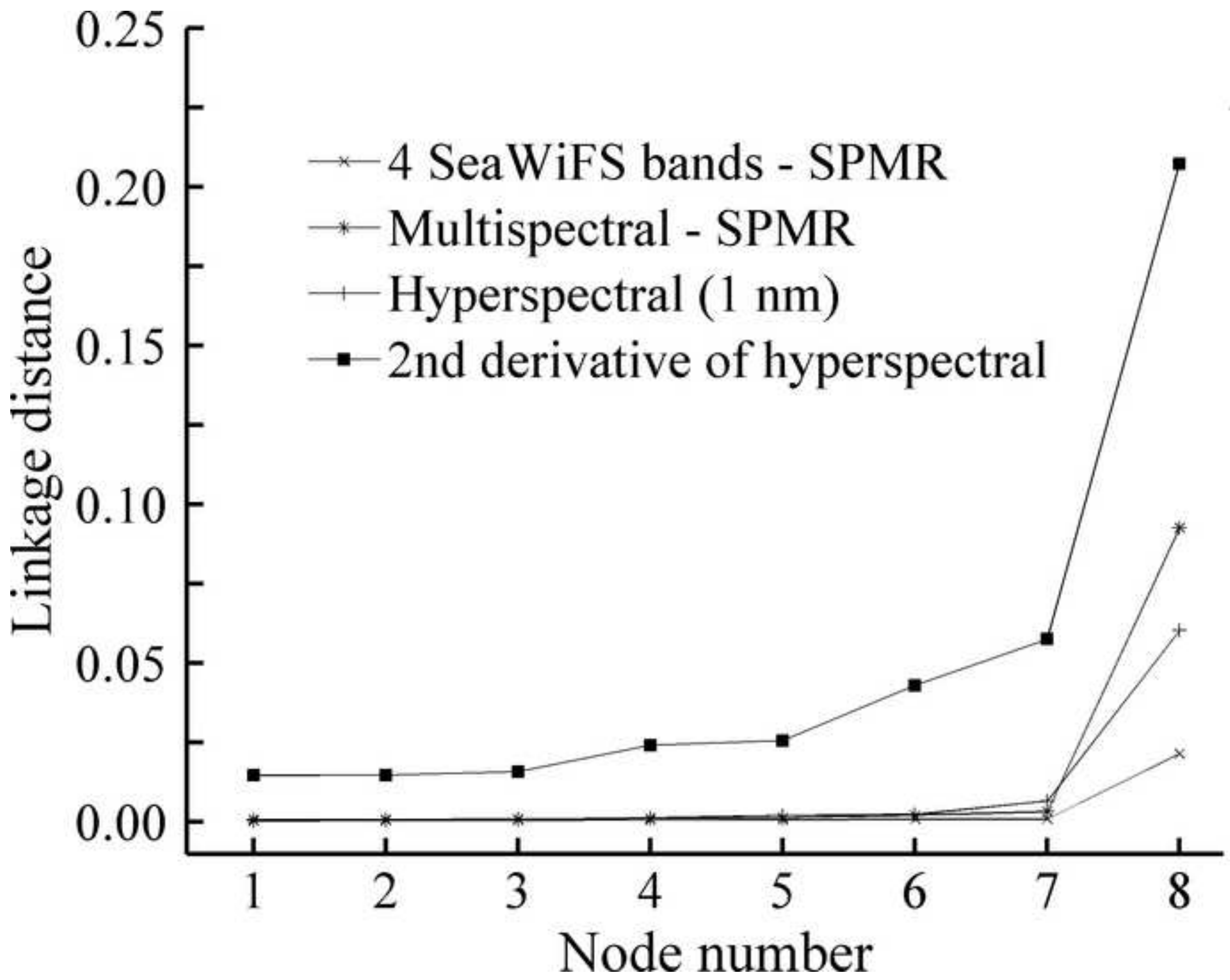



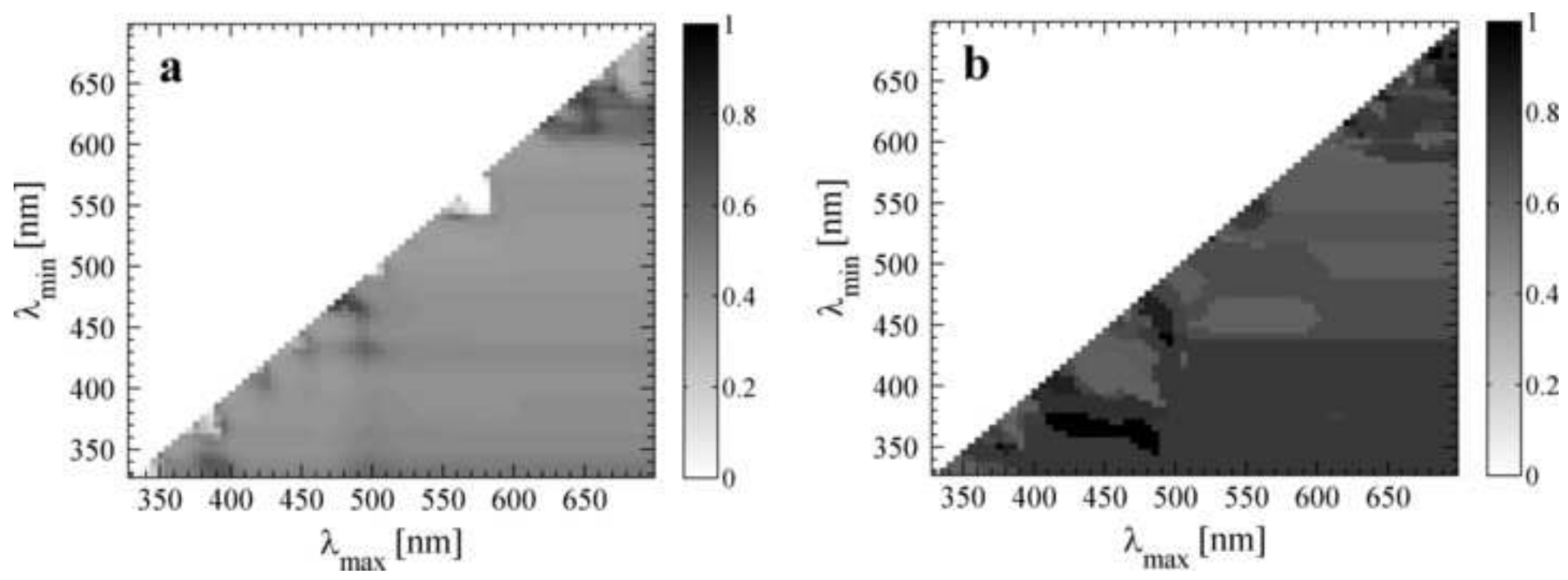


\section{Figure 15}

Click here to download high resolution image
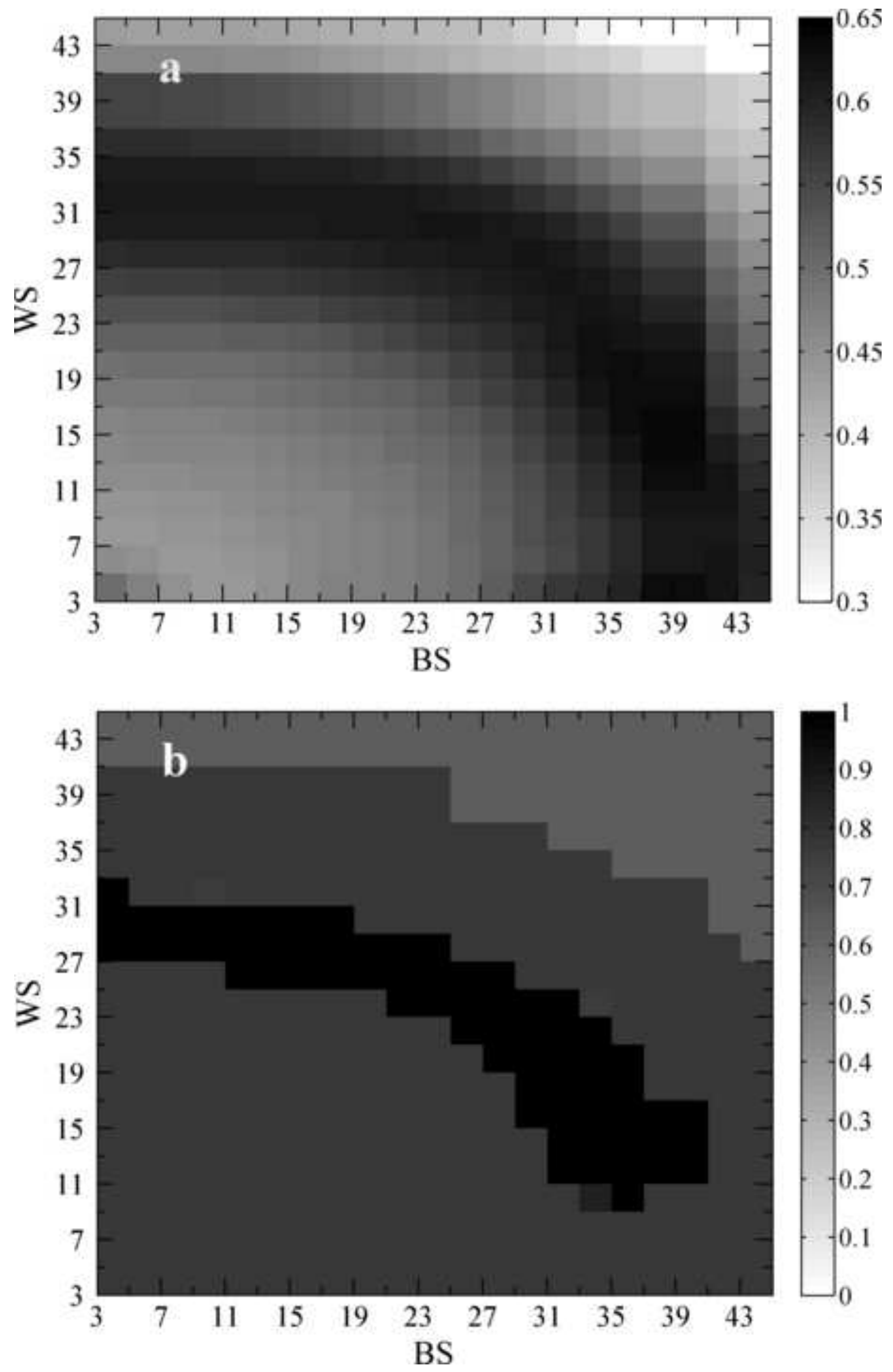
Click here to download high resolution image
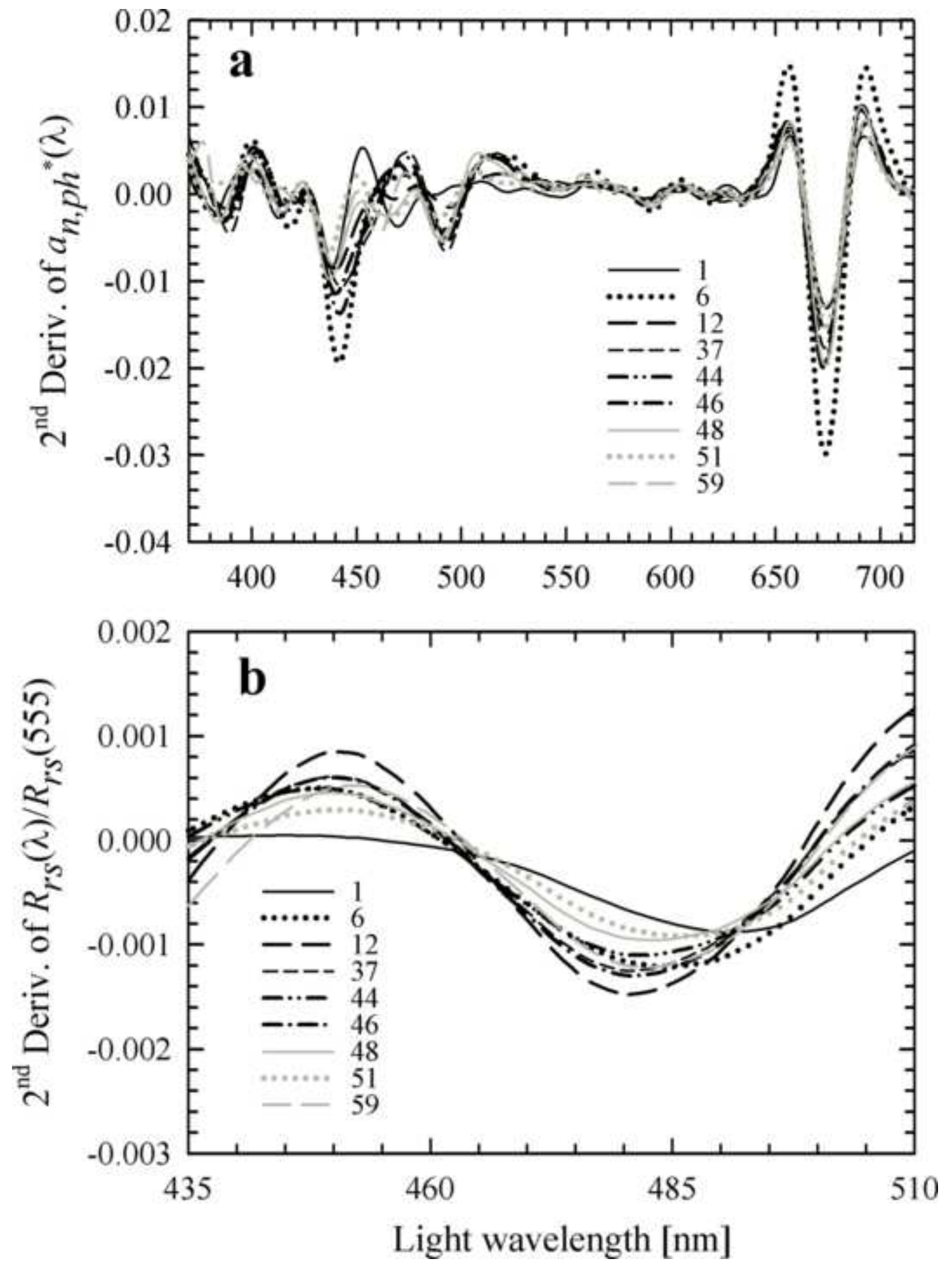